\title{
Early Warning in South Asia-Constraints and Implications
}

\author{
Zia Mian, R. Rajaraman, M. V. Ramana
}

Geography makes ballistic missile flight times between India and Pakistan very short. This has serious consequences for the feasibility and utility of possible early warning systems that could be set up in India or Pakistan to detect incoming missiles from the other side. In this article, we show how one can estimate the time taken for a missile flight from expected launch sites to targets, both analytically and numerically. We find the flight time can be as little as 300 seconds. Then we examine the two standard technologies for detecting incoming missiles - radars and geostationary satellites with infrared detectors-keeping in mind the state of the art likely to obtain in the two countries. Our calculations indicate that the warning times provided by the two methods are roughly equal to one another and, given our estimates of missile transit time, are at best enough for confirming the signals as genuine. There would be no time at all for consultations or deliberation by decision makers. Any response would have to be predetermined and automatic. If such an automatic response involves a launch on warning posture, as is the case with the U.S. and Russia, there is a significant likelihood of accidental nuclear war from false alarms.

Received 27 June 2003; accepted 19 July 2003.

R. Rajaraman thanks Professors Frank von Hippel and Hal Feiveson and the Program on Science and Global Security, Princeton University, for supporting his visits and for their warm hospitality. The authors also thank Frank von Hippel and Harold Feiveson, as well as George Lewis, David Wright, Ted Postol, Pavel Podvig, and Juergen Altmann for useful comments and helpful discussions.

Address correspondence to Zia Mian, Program on Science and Global Security, Princeton University, 221 Nassau St., Princeton, NJ 08542.

Zia Mian, Program on Science and Global Security, Princeton University, Princeton, NJ 08542.

R. Rajaraman, School of Physical Sciences, Jawaharlal Nehru University, New Delhi 110067, India.

M. V. Ramana, Program on Science and Global Security, Princeton University, Princeton, NJ 08542. 


\section{INTRODUCTION}

Having tested their nuclear weapons and missiles, India and Pakistan now seem intent on establishing command and control of their arsenals, including early warning systems. India's 1999 Draft Nuclear Doctrine proposed setting up "effective intelligence and early warning capabilities," that would use "space based and other assets" to provide "early warning, communications, damage/detonation assessment." India has started acquiring key components of such an early warning network, including the Green Pine radar from Israel ${ }^{2}$ the Green Pine is also part of the Israeli Arrow antiballistic missile system that India has expressed an interest in. ${ }^{3}$ India is developing a capability to launch geosynchronous satellites, which could serve to provide infrared detection of missile launches (as is done by the United States' Defense Support Program early warning satellites). In late 2001, India also launched a Technology Experiment Satellite (TES) with a high resolution imaging camera reportedly capable of "sensitive defense surveillance applications." 4 India is in the process of purchasing a Phalcon airborne early warning system from Israel. ${ }^{5}$ However, the Phalcon system is primarily used to track aircraft. Since our focus is on systems that could potentially provide early warning of missile attack we will not discuss it here.

While Pakistan has not made public a formal nuclear doctrine, three leading statesmen warned of the "dangers of pre-emption and interception" and recommended that a "high state of alert will become more necessary as India proceeds with deployment of nuclear weapons." 6 Pakistan's Minister for Science Technology hinted at matching Indian plans for early warning when he announced that the government was preparing to launch a geostationary satellite "to meet its strategic and communication needs."7

The location of major cities in India and Pakistan, including their capitals, close to the shared border necessarily implies that missile flight times and possible warning times in South Asia will be much shorter than the times available to the United States and Soviet Union during the Cold War. This raises important questions about the relevance of early warning systems in South Asia.

In this article, we offer a technical assessment of the constraints on early warning systems in South Asia. Methods for making such assessments are well known to experts in the field, including no doubt those in the military and space establishments in India and Pakistan. However, the extent of such expertise outside narrow military science circles in South Asia is insufficient to support meaningful public debates on the proposed early warning systems. One of our aims, therefore, is to provide some simple reliable approximations, which can 
enable nonexperts to make quick back-of-the-envelope estimates that can be used to understand the capabilities of different early warning systems.

We begin by presenting calculations of missile trajectories and the corresponding flight times between locations in India and Pakistan. We do this first analytically, starting $a b$ initio within some reasonable and clearly stated approximations and then with more precise numerical calculations, particularly for depressed trajectories, which may be considered strategically optimal in some circumstances. This analysis establishes the maximum possible warning and decision time that any early warning system could provide.

This is followed by a study of detection and tracking systems that would determine the actually available warning time. We begin that section with a general introduction to radar power and range in the scan and track mode. This is applied to the Green Pine radar to estimate its range given the typical parameters of South Asian missile flights. This is followed by a discussion on the characteristics and value of low orbit imaging surveillance satellites and geosynchronous infrared early warning satellites.

Radars and infrared satellites form the hardware component of early warning systems that detect and send signals of possible incoming objects. The receipt of a signal from this network has to be followed by a well-codified sequence of steps to determine, first, whether the signal is genuinely that of an incoming missile or a false alarm, and second, the course of action to be taken in response if it is a genuine signal. All this has to be done within the short time between the warning and the missile hitting the target.

Next, we summarize the threat assessment and response procedures that have been followed by the U.S. and the U.S.S.R. (now Russia) for decades, and consider which of these steps can be meaningfully taken within the truncated decision-making time available in South Asia.

Having analyzed the different components that go into the early warning systems, we put all this technical material together in a final section to reach conclusions about the viability and advisability of such systems in South Asia.

\section{MISSILE FLIGHT DYNAMICS}

The flight of a ballistic missile may be broadly divided into three phases. The first is the "boost phase" when the rocket is powered by its burning fuel ejected backwards. After the fuel has completely burned out comes the "ballistic phase" when the residual payload of the missile is in free fall, that is, under the influence of only the Earth's gravitational force, and follows a Keplerian orbit. Finally as the payload falls back towards the earth it reenters the atmosphere. 
Motion in this last "reentry phase," as well as in the launch phase, is complicated by the air resistance in an atmosphere of varying density.

If one needs to know the trajectories of missiles to great precision, this can only be done through numerical calculations involving elaborate computer programs. However, for the purposes of making overall judgements about the utility of early warning systems, what is more useful is a set of simple and transparent recipes for estimating flight times and other features of missile trajectories. Fortunately, such simplifying approximations are made possible by the fact that, of the three phases of a missile flight, the ballistic phase has in general the longest duration. Typical boost and reentry times are of the order of one minute to two minutes. In comparison, the ballistic phase ranges from six minutes in the case of the shortest range South Asian missile flights to over 30 minutes for intercontinental ballistic missiles.

Furthermore, the ballistic phase is not just the longest portion of a missile's flight, but also the simplest to analyze mathematically. To a very good approximation, it can be treated as the motion of a body under the influence of just the gravitational force of a perfectly spherical earth. We begin with an analysis of this phase. In Appendix 1, we recall the derivation of the trajectory and flight time in this ballistic phase starting $a b$ initio from Newton's laws. ${ }^{8}$ In the main body of this section, we use these exact analytical results to derive simple analytical approximations for the flight time as a function of the target distance and rocket velocity. This will enable us to estimate to the nearest minute the flight time of missles for typical pairs of launch sites and targets of interest in South Asia. We then follow this by more accurate numerical calculations for the full trajectory including the boost and reentry phases.

\section{Ballistic Phase-Some Exact Results and Simplifying Approximations}

As derived in Appendix 1, for a purely ballistic trajectory beginning and ending at the surface of the earth of mass $M$ and radius $R$, the following results hold. If $V$ is the initial velocity of the missile, which is pointed at an angle $\gamma$ to the horizontal at burnout, and $\vartheta$ the angular range (the angle subtended by the arc connecting the launch point to the target at the center of the Earth) then:

$$
V^{2}=\frac{\mu}{R \cos \gamma} \frac{(1-\cos \vartheta)}{(\cos \gamma-\cos (\vartheta+\gamma))}=\frac{\mu}{R \cos ^{2} \gamma} \frac{1}{(1+\tan \gamma \cot \vartheta / 2)},
$$

where $\mu=\mathrm{MG}$. 
The travel time is given by:

$$
\begin{aligned}
T= & \frac{R+h}{V \cos \gamma}\left[\frac{\tan \gamma(1-\cos \vartheta)+(1-\lambda) \sin \vartheta}{(2-\lambda)\left[\frac{1-\cos \vartheta}{\lambda \cos ^{2} \gamma}+\frac{\cos (\vartheta+\gamma)}{\cos \gamma}\right]}\right. \\
& \left.+\frac{2 \cos \gamma}{\lambda\left(\frac{2}{\lambda}-1\right)^{\frac{3}{2}}} \tan ^{-1}\left[\frac{\left(\frac{2}{\lambda}-1\right)^{\frac{1}{2}}}{\cos \gamma \cot (\vartheta / 2)-\sin \gamma}\right]\right],
\end{aligned}
$$

where $\lambda=V^{2}(R+h) / \mu$.

These formulae are too cumbersome to be of use in making quick estimates. But one could make some useful and simplifying approximations. From the point of view of early warning in either Pakistan or India, the most challenging attacks are short distance ones. These could, for example, involve launch points that are military bases with big cities or national capitals as targets. Examples are Sargodha to New Delhi or Agra to Lahore, each involving a distance $d$ of about $600 \mathrm{~km}$. These correspond to a range angle $\vartheta=d / R<0.1$ radians. For such cases one can make small angle approximations $\vartheta \ll 1$ in the earlier results to obtain:

$$
V^{2}=\frac{\mu \vartheta}{R \sin 2 \gamma}=\frac{V_{\mathrm{esc}}^{2} \vartheta}{2 \sin 2 \gamma},
$$

where we have written the rocket's burnout velocity $V$ in terms of the "escape velocity" $V_{\text {esc }}$ needed for an object to escape from the Earth's gravitational field to infinity. It satisfies $V_{\mathrm{esc}}^{2}=2 M G / R=2 \mu / R$ and numerically equals about $11.18 \mathrm{~km} / \mathrm{sec}$.

For the optimal trajectory, ${ }^{9}$ we see from (A1.11) that the boost angle $\gamma_{\text {op }}$ reduces, in the small $\vartheta$ limit, to $\pi / 4$ (i.e., $45^{\circ}$ ). Then Eq. (3) simplifies even further for the optimal velocity (for a given range $\vartheta$ ) to:

$$
V_{\mathrm{op}}^{2}=V_{\mathrm{esc}}^{2} \vartheta / 2
$$

In this small $\vartheta$ approximation an even more drastic simplification results in the lengthy but exact expression (Eq. 2) for the time of flight $T$. In the limit $\vartheta=d / R \ll 1$, (Eq. 2 ) reduces to:

$$
T=\frac{R \vartheta}{V \cos \gamma}=\frac{d}{V_{x}}
$$


where $V_{x}$ is the horizontal component of the velocity at the start of the ballistic phase and $d$ is the horizontal distance. This is just the flat earth formula for the time as distance divided by speed and it is reassuring that the lengthy exact formula in (Eq. 2) reduces in the small range limit, as it should, to the naïve flat earth result. If further the burnout velocity and tilt are taken to be optimal for the given range, then the flight time, now a function only of $\vartheta$, becomes:

$$
T=\left(\frac{2 R}{V_{\mathrm{esc}}}\right) \sqrt{\vartheta}
$$

Equations (4) to (6) are very useful for quick estimates for short range flights. Thus (Eq. 3) tells us that the required burnout speed of the missile, for any given value of the tilt angle $\gamma$ increases with the square root of the range. Eq. (5) tells us that for a given burnout speed and tilt, the flight time is proportional to the distance. That is trivial and obvious. But (6) tells us that, if you wish to compare the flight times for different ranges, but with the optimal rocket burnout velocity in each case, then $T \propto \sqrt{ } \vartheta$. Thus, the fact that the distance from Sargodha to Delhi is about $7 \%$ percent of the typical US-USSR ICBM range does not mean that the flight time will correspondingly also be lowered to $7 \%$; one must take into account the fact that the burnout velocities of the longer range rockets are also higher. The ratio of the two flight times is approximately proportional to the square root of the two ranges. The optimal burnout velocities and flight times in this small angle approximation are given in Table 1 for different examples.

We see that for the shortest-range cases, Sargodha-Delhi and Agra-Lahore, the ballistic phase lasts about 350 seconds, approximately six minutes. Adding a minute for the launch phase, and another minute for the reentry phase, the total flight time would be about eight minutes. ${ }^{10}$ Table 1 also shows similar results for other examples of increasing range, with the longest corresponding to the hypothetical attack launched from some airbase (such as Malir) near Karachi, on Thiruvananthapuram, a likely site for India's strategic nuclear command center. ${ }^{11}$

To estimate the accuracy of the small angle approximation, consider the Karachi-Thiruvananthapuram case where the distance is about $2000 \mathrm{~km}$ and corresponds to a range angle $\vartheta$ of 0.314 . The ballistic flight time calculated from the full formula in Eq. (2) is 701 seconds, compared to 645 seconds in the simple small angle approximation. This is only a $10 \%$ error. For shorter distances, the error will be much less. In the Sargodha-Delhi case, the small angle approximation is good to about 10 seconds. For analyzing policy issues related to early warning, which is the aim of this study, such accuracy is adequate. 


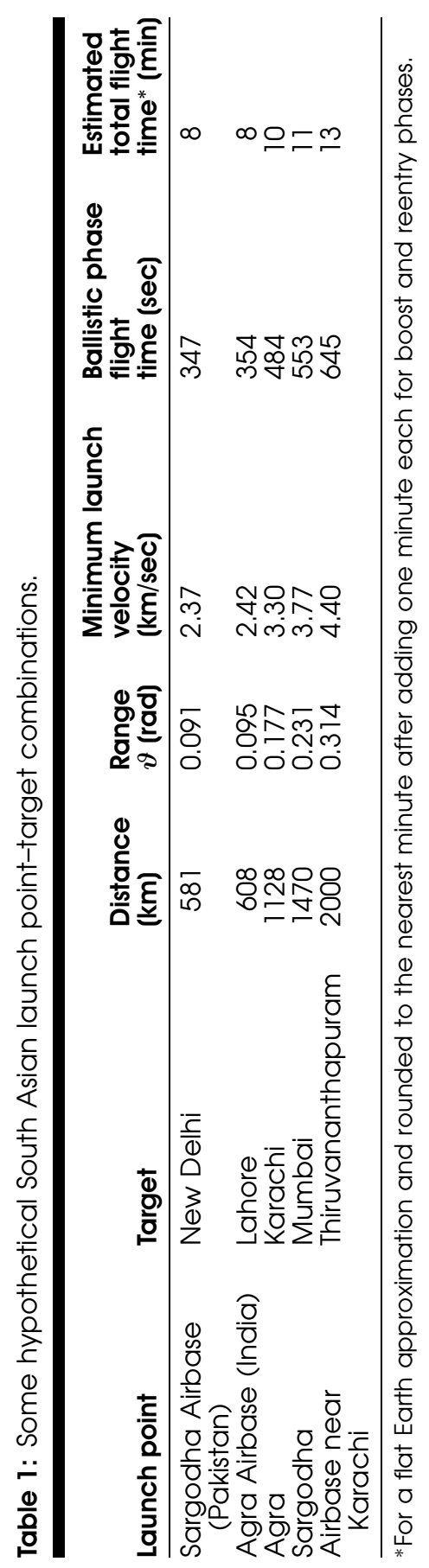




\section{Earth's Rotation and Oblateness}

The elementary derivation of the trajectory given above is, strictly speaking, valid only in an inertial frame. Thus, the velocity and angular range used in Eqs. (1) and (2) refer tacitly to values in some inertial frame. That is not the same as the Earth-fixed frame because of the rotation of the Earth. To make our results operationally useful one has to rewrite them in terms of variables in the more familiar Earth-fixed frame. The earth rotates at an angular frequency of $7.29 \times 10^{-5}$ radians per second. For an object at the equator on the surface of the Earth (of radius $R=6370 \mathrm{~km}$ ), this rotation imparts, in a fixed inertial frame, an additional linear velocity of about $0.464 \mathrm{~km} / \mathrm{sec}$ along the latitude. This is 15-25\% of the typical velocity of short and intermediate range missiles which are in the $2-3 \mathrm{~km} / \mathrm{sec}$ range and therefore not negligibly small in comparison. However, as far as the missile travel time is concerned, the effect of the change in missile velocity due to earth's rotation will be partly offset by the fact that the location of the target, in an inertial frame, has also changed. For example, if the missile trajectory flows in the same sense as earth's rotation, then the effective velocity of the missile is enhanced by this rotation. But the target has also moved farther away in the inertial frame. These compensating features considerably reduce the effect of earth's rotation on the transit time.

An analytical demonstration of these compensating effects of earth's rotation and a calculation of the residual change in missile travel time will not be easy to do in general. Apart from the fact the general formulae linking the travel time to the range and boost velocity, given in Eqs. (1) and (2) are unwieldy, one has the additional complication that these variables are interrelated. For instance in Eq. (2), valid in the inertial frame, the transit time depends on the angular separation $\vartheta$ between a given launch site and target. Their angular separation in the earth frame is determined by just their geographical distance. But their separation in a fixed inertial frame will depend on how much the target has been displaced during missile transit due to earth's rotation, which in turn depends on the missile travel time $T$. Hence on the right hand side of Eq. (2) for the travel time $T$, the variable $\vartheta$ is itself a function of $T$. This calls for a larger set of coupled equations to be solved.

However, in the small range $(\vartheta \ll 1)$ approximation that we have used above to simplify expressions, it is possible to estimate analytically the effect of earth's rotation on missile travel time. This is presented in Appendix 2, in which we examine the case where the launch site and the target lie on the same latitude. It is shown there that the Earth's rotation alters the transit time only by 2-3\%, amounting to about 12 seconds in the case of a $600 \mathrm{~km}$ flight, the distance from Sargodha to Delhi. Though that result is true only for the specially convenient 
case of a latitudinal orbit, it indicates that in general for short distance flights, the effect of earth's rotation on transit time will be only a few percent.

Another correction could come from the fact that we have assumed the Earth to be perfect sphere and taken its gravitational force to be strictly of the $1 / r^{2}$ form. In reality, the Earth is not a perfect sphere but is slightly oblate; it is flattened at the poles and bulges at the equator. This produces corrections proportional to the higher harmonics, the first term of which has the value $J=0.0016370 \pm 0.0000041$ with the second term smaller by a factor of over a hundred..$^{12}$ Once again, this is not significant enough to affect any issues of early warning strategy or policy.

\section{Minimization of Missile Flight Time and Depressed Trajectories}

The most significant challenge to early warning systems would come from missiles with short flight times. It is possible to choose missile flight trajectories that minimize the flight time rather than maximizing the range to which the missile could fly. ${ }^{13}$ Heuristically, as evident from Eq. (5), this would require a larger value of $\cos (\gamma)$, which in turn means a lower value of $\gamma$. Trajectories with values of $\gamma$ lower than the optimal value are called depressed trajectories. Since a larger fraction of the missile trajectory is at lower altitudes where the atmospheric density is higher, atmospheric drag becomes more significant. ${ }^{14}$ We therefore solve the equations of motion numerically for such trajectories. The details are in Appendix 1.

For our sample calculation, we choose the following parameters (some of these have been previously used to model Pakistan's Ghauri missile). ${ }^{15}$

The difference between characteristics of a minimum time trajectory and a maximum range trajectory are shown in Table 3 for the parameters given in Table 2 .

It is satisfying to note that the maximum range trajectory given in Table 3 compares well with the analytical result for the flight path between Agra and

Table 2: Assumed missile parameters.

\begin{tabular}{ll}
\hline Physical quantity & Value \\
\hline I-sp & $240 \mathrm{~s}$ \\
m-body & $2300 \mathrm{~kg}$ \\
m-propellant & $13000 \mathrm{~kg}$ \\
m-payload & $1000 \mathrm{~kg}$ \\
Burnout time & $95 \mathrm{~s}$ \\
Radius of missile body & $0.6 \mathrm{~m}$ \\
Radius of base & $0.5 \mathrm{~m}$ \\
Radius of nose & $0.1 \mathrm{~m}$ \\
Cone angle & 0.2 radians \\
\hline
\end{tabular}


Table 3: Minimum time and maximum range trajectories.

\begin{tabular}{lcc} 
& Minimum time & Maximum range \\
\hline Actual range $(\mathrm{km})$ & 611.3 & 1081.7 \\
Time of flight $(\mathrm{s})$ & 301.7 & 556.4 \\
Burnout velocity $(\mathrm{km} / \mathrm{s})$ & 3.0 & 2.94 \\
Burnout angle & 11.4 & 37.5 \\
Maximum altitude $(\mathrm{km})$ & 54 & 250 \\
Reentry angle & -17.1 & -40.7 \\
\hline
\end{tabular}

Karachi in Table 1 (range $1128 \mathrm{~km}$, total flight time 10 minutes). However, the flight time of about 300 seconds for a depressed trajectory with a range of about $600 \mathrm{~km}$ is significantly shorter than the eight minutes derived analytically for the $600 \mathrm{~km}$ path from Agra to Lahore in Table 1.

Two key requirements on missile trajectories are that the missile and its payload not be subject to excessive stresses due to aerodynamic loading during the boost and reentry phases, and the heating during reentry does not increase the temperature of the payload beyond acceptable values. The numerical calculations also show that the maximum drag force that occurs during reentry is much smaller in the case of depressed trajectories than in the case of maximum range (optimum burnout angle) trajectories because the latter rise to a greater altitude. Considerations of heat produced during reentry are beyond the scope of this article. In any case, details about what heating the payload can tolerate are not publicly available. But heating is not expected to be a major challenge, since it can be dealt with in a relatively straightforward manner by the use of a small ablation layer on the nose cone. The resulting mass and accuracy penalties would not be significant.

To summarize, depressed trajectories permit shortened missile flight times. In the case of key launch points and targets in Pakistan and India, flight times will be as little as 300 seconds. This is a challenge that early warning systems in South Asia would have to contend with.

\section{RADARS}

Radars form an important part of early warning systems. A radar in its essence consists of an antenna that emits electromagnetic wave pulses, some of which impinge on the potential target. Some fraction of this signal is reflected back towards the radar. Based on this reflected signal, one can calculate the location and speed of the target. The frequencies of the electromagnetic wave used by different radars vary within the range from a $\mathrm{MHz}$ to $100 \mathrm{GHz}$, or a wavelength of $3 \mathrm{~mm}$ to $300 \mathrm{~m}$. Some radars use more than one frequency for different purposes. 
The basic theory of radars is discussed in standard texts. ${ }^{16}$ The radar equation can be derived from elementary physics and has been outlined in Appendix 3 . As shown there the range $R_{d}$ of a radar in the scanning mode is given by the expression:

$$
R_{d}=\left(\frac{t_{s} P_{\mathrm{ave}} \sigma A}{4 \pi \Omega_{s} k T_{s} L\left(\frac{S}{N}\right)}\right)^{\frac{1}{4}}
$$

where $\sigma$ is the radar cross section of the target and all other quantities except $S / N$ are parameters of the radar system used. In particular, $A$ is the area of the radar receiver, $t_{s}$ the scan time, that is, the time taken by the radar to scan the entire intended region of the sky once, $P_{\text {ave }}$ the average power emitted by the radar, $T_{s}$ the noise temperature, $\Omega_{s}$ the angular search region in the sky and $\mathrm{L}$ the system loss factor. Given a particular target, all the quantities in Eq. (7) are determined except the signal to noise ratio $\mathrm{S} / \mathrm{N}$ whose value has to be decided upon judiciously.

There are competing demands on the acceptable level of the $S / N$ ratio. On the one hand, the radar should aim at detecting all potential targets. This probability is enhanced by allowing small values of the signal $S$. This implies as small a value as possible for the ratio $S / N$ since the noise level $\mathrm{N}$ of a given radar is fixed by its design. At the same time, one should minimize the probability of electronic false alarms, wherein noise is mistaken for a signal from a real target. A decrease in the required $S / N$ increases the risk of false alarms. An optimal choice would compromise between the two requirements of reliability and credibility of detection. Once a $S / N$ ratio has been decided upon, it fixes through Eq. (7) the maximum range $R_{d}$ beyond which an object with a given radar cross section $\sigma$ cannot be detected. Figure 1 (reproduced from Skolnick, 1980 ) gives the $S / N$ ratio needed for different probabilities of detection and false alarm. ${ }^{17}$ Typically missile early warning radars use $S / N$ values of 20 to 30. A $S / N$ value of 25 , for instance, would translate to a false alarm probability of about $10^{-7}$ for a detection probability of $90 \%$.

Finally, it is worth noting that any radar system must contend with unwanted and unpredictable signals. A flock of birds, for example, could produce significant radar clutter. Apart from birds and so on, radar signals could be reflected even from regions of the atmosphere where no apparent reflecting sources exist. Such signals have been dubbed "angels" or "ghosts."18 For example, atmospheric and meteorological inhomogeneities can, through discontinuities of refractive index, provide angels. Rain and clouds may also affect performance, depending on the radar wavelength. All of these imply that detection of missiles by radars is not a straightforward or fully reliable process. 


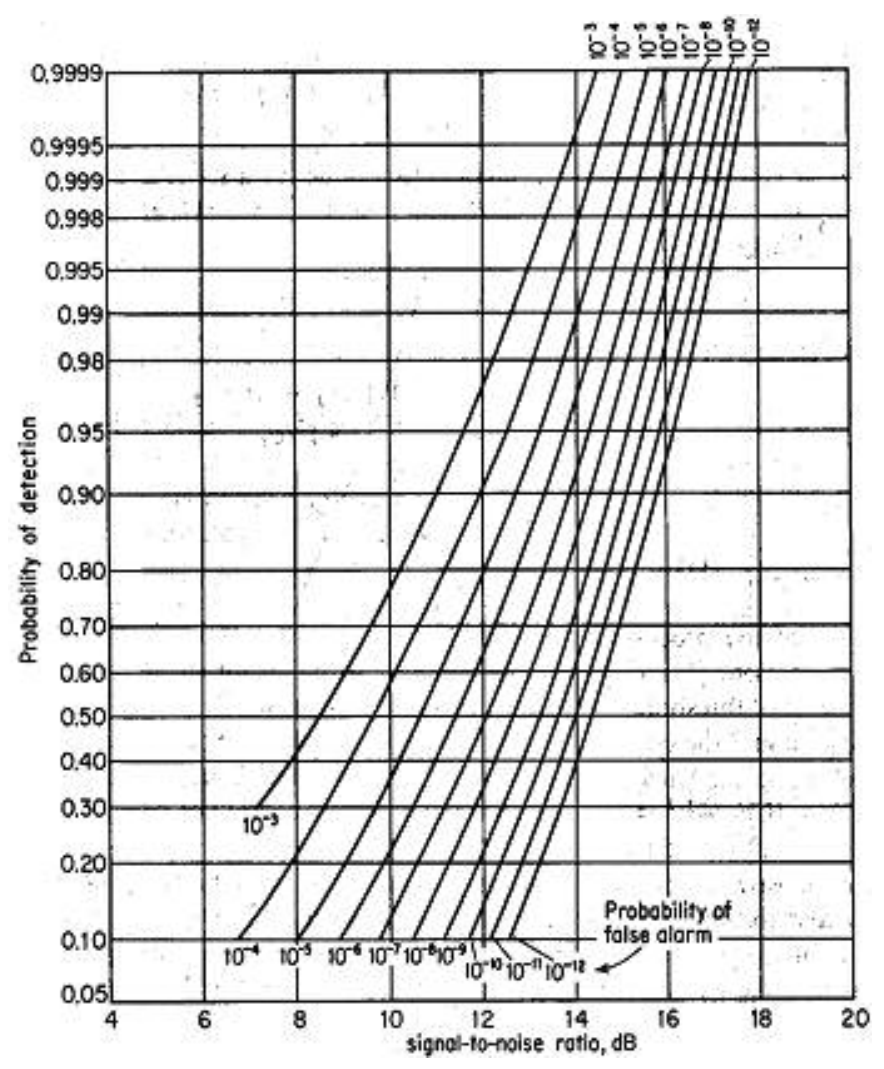

Figure 1: Probability for detection versus false alarms.

\section{Radar Range}

In order to estimate the amount of early warning possible in South Asia, we need to first figure out where the radar might detect a missile. To do this precisely, one needs the precise values of the (radar) parameters in Eq. (7). Such information is not fully or authoritatively available in the public domain, and therefore, we have to assemble plausible values for them through educated guesswork. In June 2002, Defence Secretary Yogendra Narain confirmed that India "had acquired a Green Pine radar" from Israel. ${ }^{19}$ Since this is a fairly advanced system, we will assume that this would form part of the Indian early warning system. However, most of the specifications (except for antenna area and wavelength band) of the Green Pine are not publicly available.

There are, however, a number of other radar systems around the world that are used for early warning or as part of antiballistic missile systems. In 
Table 4: Parameters of well known radars and assumptions for our calculations.

\begin{tabular}{llll}
\hline & Pave paws & Patriot & Our assumed parameters \\
\hline Average power $(\mathrm{kW})$ & 150 & 10 & 100 \\
Antenna area $\left(\mathrm{m}^{2}\right)$ & 767 & 4.5 & $12 \times 4.8\left(\mathrm{~m}^{2}\right)$ \\
Wavelength $(\mathrm{m})$ & 0.7 & $0.05-0.08$ & $0.21-0.25$ \\
Bandwidth & $100 \mathrm{kHz}$ & $100 \mathrm{kHz}(?)$ & $100 \mathrm{kHz}$ \\
Scan time (s) & $\mathrm{NA}$ & 7.5 & 4 \\
Search angle (Azimuth) & $120^{\circ}+120^{\circ}$ & $90^{\circ}$ & $120^{\circ}$ \\
Search angle (elevation) & $3^{\circ}-80^{\circ}$ & $20^{\circ}-70^{\circ}$ & $3^{\circ}-20^{\circ}$ \\
\hline
\end{tabular}

Sources: Countermeasures (Cambridge, USA: Union of Concerned Scientists, 2000); Theodore A. Postol, "Lessons of the Gulf War Experience With Patriot," International Security vol. 16, no. 3 (Winter, 1991/92), pp. 119-171, "AN/FPC115 PAVEPAWS Radar" available at 〈http://www.fas.org/spp/military/program/track/pavepaws.htm〉; M. D. Lok, "Israel: Aerospace in Depth," Jane's International Defense Review (2002), pp. 38-48; Jurgen Altmann, "SDI for Europe? Technical Aspects of Anti-Tactical Ballistic Missile Defenses," PRIF Research Report 3 (1988); Michael O'Hanlon, "Terminal defense and nuclear deterrence: Technical considerations," Princeton University Thesis (1987).

Table 4 we list the parameters for two radar systems. The first is the PAVE PAWS system that is used as part of the U.S. early warning for ICBM launches from Russia. The second is the Patriot that was used extensively in the First Gulf War in 1991 to detect and track incoming Scud missiles. Despite the vast differences in their purpose, many of the parameters are somewhat similar. This helps us choose a representative set of parameters (listed in Table 4) for our hypothetical radar for a South Asian early warning system.

Equation (7) shows that the radar range does not depend strongly on the target cross section. It is proportional only to the one-fourth power of $\sigma$. But the values of $\sigma$ can vary by several orders of magnitude, even for a given missile flight, depending on the stage of the flight and the angle of slant. Correspondingly, the range can vary considerably.

In Appendix 3 we give a brief discussion of radar cross sections. As discussed there, $\sigma$ is not just the geometrical cross section that the target presents to the radar. Rather it is a measure of how much radiation the target actually reflects back towards the radar. Its value therefore depends not only on the shape and size of the target but also on the wavelength of the radar waves, since diffractive effects will play a role.

The largest cross section for a given missile would correspond to its full body side-on view. For a typical missile of interest to our analysis, we estimate this radar cross section to be about $188 \mathrm{~m}^{2}$ (see Appendix 3). This could be further increased by the presence of fins and ionization from the exhaust. Of course a side-on view of the full missile is possible only if the radar observes it in a near vertical position around launch. Because the radar cannot see below the horizon (discussed in greater detail later on) a ground-based radar cannot 
Table 5: Ranges for radar detection of missile at different stages of flight.

\begin{tabular}{lcr}
\hline Type of target & Cross section & Range \\
\hline "Nose-on" & $0.01 \mathrm{~m}^{2}$ & $229 \mathrm{~km}$ \\
Re-entry vehicle "Side-on" & $1 \mathrm{~m}^{2}$ & $725 \mathrm{~km}$ \\
Full missile body (Launch phase) & $100 \mathrm{~m}^{2}$ & $2292 \mathrm{~km}$ \\
\hline
\end{tabular}

see the ground-based launch of a missile hundreds of miles away. It would have to wait for the missile to rise above the horizon. But by then the missile would have tilted towards the horizontal, offering a smaller cross section.

The cross section, and therefore the radar range, will be the least if detection occurs only when the reentry vehicle is approaching nose-on at the target/radar. We estimate a typical nose cone cross section to be about $6 \times 10^{-3} \mathrm{~m}^{2}$ (see Appendix 3). In between these extremes, one can have intermediate values if the radar detects, say, the reentry vehicle side-on, instead of the full missile with its rocket engines.

Thus the cross section for a missile can vary from a hundredth of a square meter to hundreds of square meters. Correspondingly the range up to which a given radar can see such targets will also vary, although only by the one-fourth power of $\sigma$. In Table 5 we present approximate values for the radar range for these different domains of cross section, using the radar parameters listed the third column of Table 4 with $L=10, S / N=20$ and Noise Temperature = $1200 \mathrm{~K}$.

Thus, if all factors are favorable, the range may in principle be of the order of $2000 \mathrm{~km}$. However, as mentioned already, because of the curvature of the Earth a radar cannot see objects located below its horizon. Further, to reduce ground clutter (reflections from objects on the ground and so on) the radar does not scan angles below a certain minimum angle. The Pave Paws radar beam, for example, goes only as low as 3 degrees to the horizon. ${ }^{20}$ Figure 2 shows two curves. The dotted curve represents the above-the-horizon-altitude as function of distance corresponding just to the Earth's curvature. The second curve gives the same, with an extra 3 degrees of elevation to avoid clutter. We see for instance that if the radar is at a distance of 300 kilometers from the target, then it can only see missiles that are at an altitude of about 20 kilometers or greater.

To illustrate, consider the first case mentioned in Table 1 of a missile launched from Pakistan's Sargodha air force base (A32:03N, 72:39E) headed towards New Delhi, which is detected by a radar kept at India's Ambala air force base (A30:22N, 76:48E). ${ }^{21}$ The distance between Sargodha and Ambala is $437 \mathrm{~km}$. At this distance, the effective radar horizon (including a clutter angle 


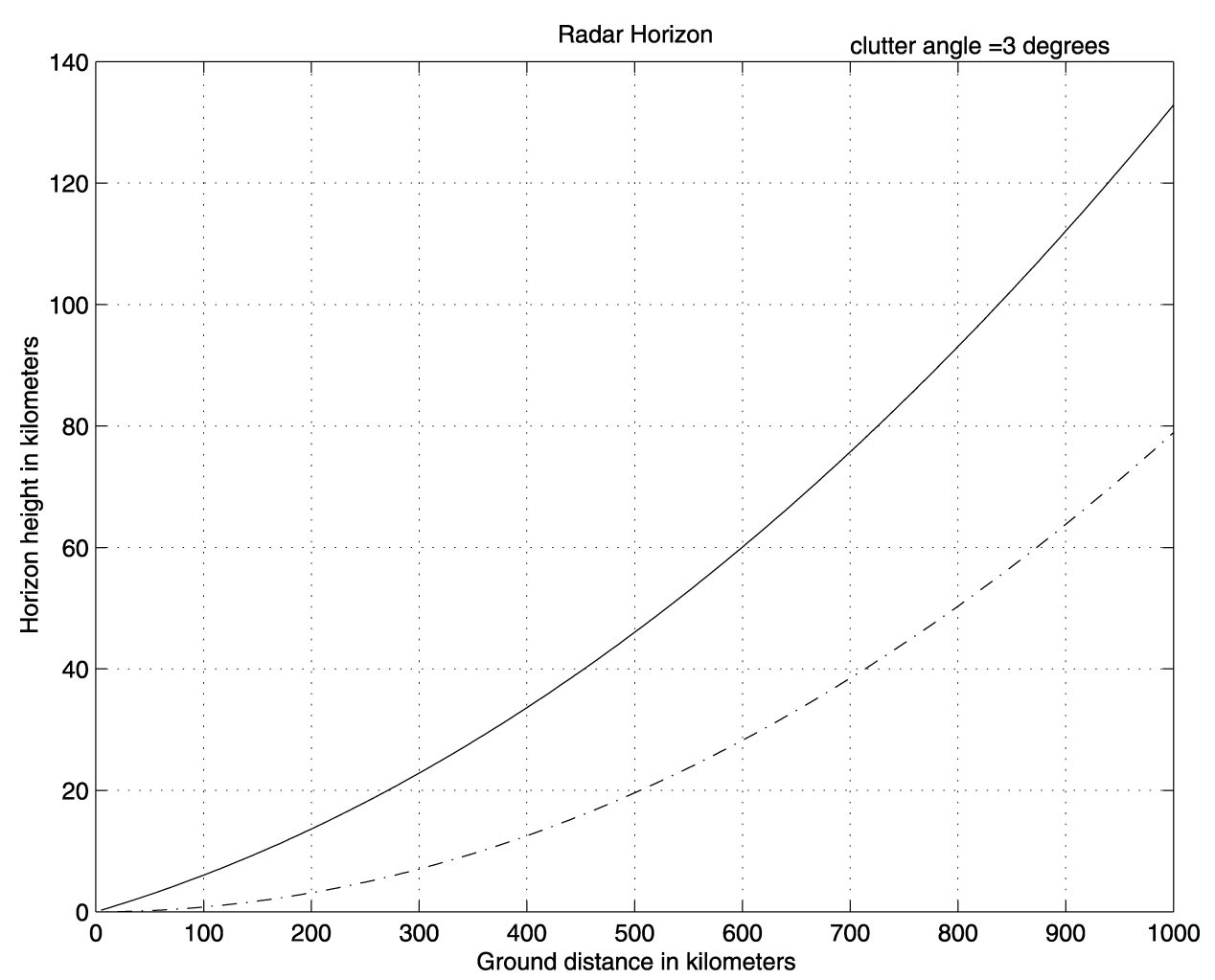

Figure 2: Radar horizon as a function of distance.

of 3 degrees) is $38 \mathrm{~km}$. The missile cannot be detected at a lower altitude at that distance, that is, it cannot be detected any sooner into its trajectory. Consequently, a fraction of the missile flight time is inevitably over before detection is possible. Furthermore, the height of $38 \mathrm{~km}$ mentioned above is relevant only if the missile travels entirely vertically until detection. In reality it will tilt towards the horizontal, and travel towards the target and radar, allowing for detection at a lower height. For the case that we have chosen with the missile flying from Sargodha towards New Delhi, a numerical calculation shows that the earliest that detection can take place is around 87 seconds after launch and at an altitude of $30.5 \mathrm{~km}$ along the (depressed) trajectory. ${ }^{22}$

The radar also provides an estimate of the radial velocity of the missile by measuring the Doppler shift in the reflected radar wave. ${ }^{23} \mathrm{Gimbal}$ axis sensors can provide the angular components of the velocity. Measuring the velocity also helps distinguish a missile from other targets such as airplanes or a flock of birds because of the high velocity of the former. 
Detection of a missile soon after launch is itself insufficient to serve as early warning of a missile attack; for example, states with missiles frequently conduct flight tests. To determine the trajectory accurately in the face of various errors and decide if the missile is heading towards a target within one's own country, one needs to track it over a period of time. We estimate that this should be about 20 seconds.

All this would imply that the radar systems can provide relatively unambiguous detection, and thus warning, at best about 110 seconds after the missile's launch. Given that the total time of flight along a depressed trajectory is about 300 seconds, this would leave about 200 seconds for all subsequent assessments and responses.

\section{EARLY WARNING SATELLITES}

Satellites have been an important component of early warning systems for the United States and Russia to provide the first detection of missile launches. France is also in the preliminary stages of building an early warning satellite system. ${ }^{24}$ In South Asia, India and Pakistan have expressed an interest in setting up satellite-based early warning.

India has a well-established satellite program. ${ }^{25}$ It was initiated as the Indian National Committee for Space Research in 1962 as part of the Department of Atomic Energy. It is now managed by the Indian Space Research Organisation (ISRO) and the Department of Space.

Pakistan's space program is managed by the Space and Upper Atmosphere Research Commission (SUPARCO), originally created in 1961 as part of the Pakistan Atomic Energy Commission. Pakistan has no satellite launch capability. It has one satellite in low earth orbit, the Badar-II.

\section{Geosynchronous Infrared Satellites}

As part of its early warning system, the United States developed a series of Defense Support Program (DSP) satellites, able to detect the heat of a missile plume against the background radiation emitted by the earth and clouds. ${ }^{26}$ These satellites are in geosychronous orbit, at an altitude of about $36,000 \mathrm{~km}$, with a period of one day, and so they seem to stay above one point on the Earth. ${ }^{27}$ The DSP satellites also carried optical, florescence, and X-ray detectors to locate nuclear explosions on the Earth's surface, in the atmosphere and in space. ${ }^{28}$

These satellites are able to determine "within minutes" the location, time, yield and yield to mass ratio of a nuclear detonation. ${ }^{29}$ The DSP satellites rotate six times a minute, sweeping the sensor's field of view around the earth so that 
it covers almost an entire hemisphere. Any strong source is thus picked up every 10 seconds. Multiple observations serve to confirm that it is a missile and estimate its trajectory, and its impact area. The DSP system in the early 1980s was able to detect the number of launches, determine the launch site and the missile's azimuth sufficiently well as to ascertain if it was headed towards the United States. ${ }^{30}$

The area viewed by a given DSP satellite is about 200 million square $\mathrm{km}$, roughly $40 \%$ of Earth's surface area. A U.S. DSP satellite launched in May 1971 into orbit, at $65^{\circ} \mathrm{E}$ longitude, was able to cover much of Europe, almost all of Africa, the middle east, Russia, central Asia, and south and south east Asia. ${ }^{31}$ A subsequent satellite DSP F-7, again at $65^{\circ} \mathrm{E}$, had coverage very similar to what India might seek if the aim were to monitor missile launches and nuclear detonations involving Pakistan and China and the Indian ocean. ${ }^{32}$

The infrared detectors on the DSP satellites attempt to pick up the radiation from the hot exhaust gases that make up a ballistic missile's plume close to the Earth's surface. But, like the terrestrial sources which can be mistaken for or mask the missile plume signature such as flying aircraft, industrial furnaces, fires, and so on, infrared radiation from missile plumes is largely absorbed by water vapor and carbon dioxide in the lower atmosphere. ${ }^{33}$ The radiation is also scattered by rain and heavy dust and does not penetrate clouds. ${ }^{34}$ Thus, a missile can be reliably detected only when it emerges above the cloud layer. The cloud-top at latitudes of $20^{\circ}-40^{\circ} \mathrm{N}$ (i.e., covering Pakistan and northern India) is typically at altitudes of $3-4 \mathrm{~km}$, but can be as high as $10 \mathrm{~km} .^{35}$

Once the missile has risen above the clouds, the signal from the plume is still not easily distinguished from the normal background heat radiated from the Earth and solar radiation reflected from the cloud tops. The Soviet Union sought a look-down capability equivalent to the U.S. DSP satellites starting in 1979, and the first Soviet satellite with this capability was launched in 1991 with limited success; as late as 2002, it was still described as "an essentially experimental program." 36 Instead, the Soviet Union relied throughout the 1980s on a system of satellites in very elliptical orbits that did not look directly at the Earth but waited for the missile plume to become visible against the background of space.

The experience of U.S. DSP satellites suggests some of the operational problems. A Congressional study of failures of the U.S. early warning system noted that the satellite system sometimes generates "unusual information" when changes are made in the position or configuration of the IR sensors. ${ }^{37}$ It also recorded that "there are many indications of [missile launch] detections that have to be evaluated but prove not to be associated with a threatening missile launch." 38 
A significant problem has been anomalous incidents of solar reflection from clouds and the ocean surface, along with ice and snow, including from high mountainous areas, which can blind the DSP satellites. ${ }^{39}$ They are reported to be "frequently put out of commission for several hours by the effects of sun glare." 40 The blind spots and occasional false alarms induced by anomalous solar reflections required the U.S. to arrange a constellation of DSP satellites where coverage "extensively overlapped" and the satellites were sufficiently far apart that the blind spots normally did not coincide; despite this, it has been noted that "false alarms continued to plague surveillance." 41 The U.S. apparently has four DSP satellites currently in geostationary orbit (DSP17, 19, 20, and 21). ${ }^{42}$ The Soviet Union's space-based early warning satellites had similar problems. ${ }^{43}$ At the very least, it would appear that with one geostationary early warning satellite, the detection of possible missile launches from an area is not certain.

India's pursuit of its Geosynchronous Satellite Launch Vehicle (GSLV), initiated in 1990, offers it the capability to launch a satellite comparable in size and weight to a U.S. DSP satellite. ${ }^{44}$ The first developmental flight, GSLV-D1, was launched on April 18, 2001. GSAT-1 was put into orbit in near-geosynchronous height. ${ }^{45}$ The satellite weighed $1540 \mathrm{~kg}$. ${ }^{46}$ The GSLV heat shield is made of aluminium alloy, is $3.4 \mathrm{~m}$ in diameter and $7.8 \mathrm{~m}$ long, and covers the payload during ascent phase. ${ }^{47}$ India tested the GSLV again in May 2003, placing a $1630 \mathrm{~kg}$ experimental communications satellite into orbit. ${ }^{48}$ Pakistan does not have an equivalent capability. ${ }^{49}$

\section{Imaging Satellites}

India launched its Technology Experiment Satellite (TES) in October 2001. ${ }^{50}$ It is in a $570 \mathrm{~km}$ altitude sun-synchronous orbit, where the satellite passes over the same part of the Earth at roughly the same local time each day. ${ }^{51}$ TES is reported to carry a one-meter resolution camera. ${ }^{52}$ This kind of satellite cannot offer early warning of the launch of a missile, but it may offer longer term surveillance data that indicates possible preparations for military action, often described as "strategic warning." TES capabilities may be similar to recent commercial imaging satellites and a brief comparison will serve to illustrate its capabilities and limitations.

A satellite similar to TES is Ikonos, a commercial 1-meter resolution imaging satellite launched in 1999. ${ }^{53}$ It images a nominal swath along the ground of $11 \mathrm{~km}$ width at nadir with a resolution of 1-meter at up to 26 degrees off-nadir. Quickbird 2, a privately-owned U.S. imaging satellite was launched in October 2001. It is reported to be capable of capturing images with a resolution as small as $0.6-0.7$ meters. and has a revisit time of between 1 and 3.5 days, depending on latitude. ${ }^{54}$ 
The low-orbital altitude and available imaging systems restrict the area such satellites can map. Earth's rotation of 15 degrees per hour causes each successive track of a satellite to cross the equator to the west of the preceding track. The shift in longitude between the tracks is the product of Earth's rate of rotation and the period of the satellite. For TES, with a period of 96 minutes, there will be about 24 degrees of regression between tracks. At the latitudes of Pakistan, roughly $24^{\circ}-34^{\circ} \mathrm{N}$, a regression of 24 degrees translates to a westward separation between successive satellite tracks of about $2,300 \mathrm{~km}$.

IKONOS has 1 meter resolution for a $600 \mathrm{~km}$ swath perpendicular to its ground track. ${ }^{55}$ The width imaged along the direction of the ground track is only $11 \mathrm{~km}$. This means complete, continuous coverage would require a constellation of such satellites moving one after the other so as to cover each $11 \mathrm{~km}$ strip as the previous satellite moved its field of view to the next strip. It would take 100 satellites to cover the $1100 \mathrm{~km}$ distance between Karachi and Islamabad. Ikonos was designed with a life span of five to seven years. ${ }^{56}$ Quickbird is fuelled for seven years. ${ }^{57}$ If TES has similar fuel loads, India will need to plan on launching TES replacements every seven years or so.

TES images could provide a military surveillance capability to the Indian Air Force. ${ }^{58}$ At 1 meter resolution many details of military significance can be obtained, including general detection of nuclear weapons systems, and precise identification of aircraft, command and control headquarters. ${ }^{59}$ These may be used to determine lists of possible military targets and to monitor the development of infrastructure and deployment of forces over a period of several weeks. The movement of military equipment (jets, tanks, ships etc.) from their bases, or between bases in a crisis could be used to assess preparations for a possible attack.

Even in this role, imaging satellites are susceptible to simple countermeasures. Since satellite orbits are regular and predictable, and their capabilities reasonably well understood, it is feasible to use camouflage, deception, windows of opportunity, and so on, to avoid giving away at least some information. ${ }^{60}$ Optical imaging satellites in particular have a number of significant inherent limitations. Working in the visible range, they can only take pictures during day time, and where there is no cloud cover. It is worth recalling that India was successful in concealing from United States spy satellites preparations for its May 1998 nuclear tests.

\section{Satellite Detection of Missile Launches}

As we have discussed, imaging satellites flying at low altitudes cannot realistically provide tactical (real time) warning of missile launches because of the small area scanned by them at any given time. By comparison a single 
geosynchronous satellite can, in principle, detect missile launches anywhere in South Asia in real time. However, to offset temporary blinding due to cloud reflections and so on, one might need additional geosynchronous satellites.

Returning to the issue of concern, as mentioned earlier, a missile launch may be reliably detected only after it rises above the cloud cover (10-20 km altitude). This will delay the detection of the missile by about half a minute to a minute. But as we have seen in the previous section, a radar like the Green Pine can detect the missile about 90 seconds after launch (for the Sargodha-Delhi case). Thus, the geosynchronous satellite could typically provide only half a minute to a minute of additional warning. This is in contrast to the U.S.-Soviet case, where the early warning satellites provided several minutes of additional warning time. Therefore, in South Asia, early warning satellites could at best provide an independent detection mechanism.

\section{EARLY WARNING AND THREAT ASSESSMENT}

An early warning system is more than the set of detectors and platforms for monitoring missile launches. It includes the procedures for evaluating the information produced by such detectors and assessing the reliability and significance of such data and interpreting it as "warning." In the preceding sections, we arrived at estimates of the maximum time that would be available for this threat assessment and subsequent warning procedures and decision-making. To understand how the initial signal may translate into a meaningful warning and response, we outline the procedures adopted by the United States and the Soviet Union (now Russia) to assess missile warnings. The flight times between the missile fields and targets of those two states are about thirty minutes. ${ }^{61} \mathrm{We}$ then look at whether analogous procedures could be practical in South Asia given the much shorter warning times.

\section{U.S. Early Warning Procedures}

In the United States, the task of detecting and assessing ballistic missile launches is managed by North American Aerospace Defense Command (NORAD). Though most of the details about its operation are secret, independent analysts have managed to construct a broadly consistent picture of the general procedures that are followed. One such reconstruction is offered by Bruce Blair based on interviews with former NORAD officers. ${ }^{62}$ This can be simplified and summarized as a sequence of events with their allotted duration:

1. Observation of missile launch by satellites in geosynchronous orbit and relay of signal to ground stations for processing (half a minute after launch). 
2. Decision by the ground station staff whether to forward this information to NORAD and other command centers assessing missile warnings (about 15 seconds).

3. Convening of Missile Event Conference at NORAD. Command director would assess the reliability of satellite data, based on telephone communications with ground station operators, who would reverify the initial detection and confirm that it was not due to equipment malfunction. Strategic warning analysts, who look at intelligence estimates of the international political and military situation, and force deployments are also consulted. The command director would then forward the level of confidence in the warning to the war rooms at the Pentagon and Strategic Command (3 minutes).

4. About four minutes after a possible missile launch, if the NORAD officer judged there was medium or high confidence in a warning, the information would go up the chain of command, that included the Joint Chiefs of Staff Chairman, and Defense Secretary, ultimately leading up to the President, and a Missile Attack Conference would be initiated. By this time, there may or may not have been separate warning from ground-based radars (4-6 minutes).

5. There would now be less than 20 minutes remaining from the initial 30-minute flight time (assuming a Soviet ICBM). This would leave about 10 minutes for discussion, before a decision would have to be made whether U.S. missiles were to be launched, rather than to ride out an attack in which the U.S. ICBMs and early warning would be possibly destroyed.

6. If the decision was made to fire U.S. missiles, it would take two minutes to send launch orders, three minutes to fire the Minuteman ICBMs, and several more minutes for the missiles to travel to a safe distance from their bases.

This timeline adds up to about 30 minutes, which is comparable to an ICBM flight time from Russia, and would enable the retaliatory missiles to take off just before the silos are destroyed. However, all of this assumes that every procedural and physical element in the early warning system works perfectly.

\section{Soviet/Russian Early Warning Procedures}

There is less information about Soviet (and now Russian) early warning systems. ${ }^{63}$ One description, again by Bruce Blair, suggests the following expected sequence of events following detection by satellites or ground-based radars of a possible missile launch: ${ }^{64}$

1. Positive attack identification from satellites (about one minute after launch) or radar would lead to a warning report by the Center for the Analysis of 
Missile and Space Situation, the Russian counterpart of NORAD, to Defense headquarters, general staff, and strategic rocket forces.

2. This center would send a signal to the President, Defense Minister, and Chief of General Staff (through the nuclear suitcase). ${ }^{65}$

3. Within 4-6 minutes after a missile launch, political and military leadership along with chief of early warning center would confer on warning.

4. If the early warning system provides dual sensor (i.e., radar and satellite) warning of attack, then general staff would send preliminary command activating communications system to nuclear forces. This communication link is normally kept disconnected. ${ }^{66}$

5. According to Russian procedures, the national command authority (President and Defense Minister) is allotted three minutes to discuss and authorize (or withhold) permission to launch Russian missiles.

6. To institute and transmit the launch order, with the unlock codes, takes about 2-3 minutes. A total of 12-13 minutes would have elapsed since incoming missile liftoff.

7. Once the order has been received it takes as long as 8 minutes for the Russian missiles to emerge from their silos. A total of about 20 minutes would have elapsed between the time of launch of the enemy attack and the launch of the Russian missiles.

Russian procedures are thus designed to beat the expected arrival time of ICBMs from the continental United States by a margin of 10 minutes. Russian concerns that these procedures may not work as planned led them to install in addition a "dead hand" that would automatically transmit launch orders. ${ }^{67}$

\section{False Warnings}

Technology and operating procedures are both fallible and can combine at times to create false alerts of early warning systems. The history of the cold war abounds with examples. In the case of the U.S., from 1977 through 1984, the only period for which official information has been released, the early warning systems gave an average of 2,598 warnings each year of potential incoming missiles attacks. Of these about $5 \%$ required further evaluation. ${ }^{68}$ A U.S. Senate report on false alerts from the early warning system noted that all 3,703 missile display conferences from January 1, 1979, to June 30, 1980, resulted from "actual pickup by warning sensors of some physical phenomena or reconfiguration of warning sensors." ${ }^{29}$ The study further observed that, in addition, the computers and communications system transmitted false information, but prior to June 1980 "records were not kept of actual incidents," and cited NORAD's 
assessment that such transmission of false information occurred perhaps two or three times a year.

In a notable 1980 case, the NORAD director was given evidence for an attack from the early warning satellites and radars, but ground station operators reported no such data was being gathered by the sensors. Strategic warning also suggested no credible threat. Faced with this, NORAD was unable to give its assessment within the required 3 minutes. It took 8 minutes to determine that there was no confidence in the warning. ${ }^{70}$

In an instance involving the Russian early warning system in 1995, a Norwegian scientific rocket launch was detected and the matter went all the way up the command chain to President Yeltsin before it was recognized not to be the precursor to an attack. ${ }^{71}$

Early warning systems in India and Pakistan will, of course, also be prone to false alarms. The shorter flight times in South Asia will limit the opportunities available to decision-makers to assess the data from their early warning systems. Thus, the risk posed by false alarms is greater than was the case in the Cold War conflict.

\section{CONCLUSION}

Our analysis suggests that in South Asia, with existing missiles, the estimated total missile flight times range from 8-13 minutes for ranges of $600 \mathrm{~km}-$ $2000 \mathrm{~km}$, respectively. In fact the time could be even less. If the missile is flown on a depressed trajectory, then the missile flight time could be as low as 5 minutes for a $600 \mathrm{~km}$ missile flight. This would clearly offer the greatest challenge to the early warning system, and for this reason it may well be adopted. We therefore focus on such trajectories. The missile flight times of 5-13 minutes encompass paths from missile launch points at airbases in both countries to the national capitals and to major military facilities, including possible locations of the nuclear arsenals or their command posts, in the other country.

The earliest that a missile on a depressed trajectory could be detected might be about half a minute to a minute after launch, provided India or Pakistan had the appropriate infrared sensors on early warning satellites in geosynchronous orbit. Neither country has this capability at present; given the experience of Russia/Soviet Union, one would expect that the development of the necessary IR sensors would be a significant challenge.

Our calculations have shown that early warning radars (such as Green Pine), if deployed in South Asia, would have sufficient range to see a missile, side-on, soon after launch-once the missile rises above the radar horizon. This detection would come within approximately half a minute after detection by a 
geosynchronous satellite. This is markedly different from the case of the U.S. and U.S.S.R/Russia, where satellites provided several additional minutes of warning.

If the satellites truly provide an independent way of observing missile launches it would reduce the risk of false alarms. However, this depends strongly on the architecture of the system. Because the warnings from the two systems would have to be evaluated together, there is a possibility of a common mode failure. ${ }^{72}$ Extra components also add to the complexity of the system making it more opaque and harder to foresee ways by which the system may not perform as designed. ${ }^{73}$ Redundancies also produce a false sense of security that may prompt decision makers to trust the system more than warranted.

In light of the above arguments, it is worth asking if early warning satellites in South Asia will serve any useful purpose.

Regardless of whether a missile launch is detected by a satellite or a radar, or both, any assessment procedures in India and Pakistan would require that information be processed, decision makers informed, and action taken within at most 4-7 minutes-for an attack targeted at the respective capital cities. Such a short period places a much more stringent constraint on procedures for evaluation and verification of any warning, and decision-making. In the case of the depressed trajectory missiles launched towards capital cities there would be at best time for the warning to be communicated to decision makers. There would be no time whatsoever to consult or deliberate after receiving this warning. There is no time for any decision as such. Any action would therefore have to rely entirely on prior planning.

There are two ways, not mutually exclusive, in which the warning coming out of the system could be used. One is to feed it directly into a missile defense system. India, for example, has been trying to acquire the Arrow system from Israel. ${ }^{74}$ If the missile interceptors do not carry nuclear warheads, it would seem that this response could be automatic and not require human decision making. The second use is to pass the warning to the military and political leadership. As we have demonstrated, they would have time only to put in motion some predetermined response.

There are two classes of predetermined responses. The first is to ride-out the possible attack and then determine the further course of action. In this case, early warning would not have served to inform decision-making in any meaningful way. The second class would be to retaliate immediately upon receipt of a warning (i.e., a launch on warning posture), which in turn requires keeping weapons on high-alert.

Indeed, it could be argued that organizational biases would predispose decision makers to use the acquisition of an early warning system for adopting 
a launch on warning posture. ${ }^{75}$ With a launch on warning posture the risks of accidental nuclear war are even more grave in South Asia than was the case in the superpower confrontation.

\section{NOTES AND REFERENCES}

1. "Draft Report of National Security Advisory Board on Indian Nuclear Doctrine," Available on the internet at $\langle\mathrm{http}: / / \mathrm{www}$.indianembassy.org/policy/CTBT/nuclear_ doctrine_aug_17_1999.html .

2. “India Acquires Sophisticated Radars from Israel," Indian Express (28 June 2002).

3. One reason for the refusal is Israel's decision to stockpile Arrow missile interceptors. Barbara Opall-Rome, "Israel Boosts Arrow Arsenal as War Looms," Defense News (November 25-December 1, 2002).

4. "TES could be India's First Eye in the Sky," Hindustan Times (24 October 2001).

5. Sandeep Dikshit, "India may get Phalcon AWACS," The Hindu (30 April 2003).

6. Agha Shahi, Zulfiqar Ali Khan and Abdul Sattar, "Securing Nuclear Peace," The News (5 October 1999).

7. “Geo-stationary satellite by year-end: Ata," The Dawn (23 January 2002), available at 〈http://www.dawn.com/2002/01/23/nat1.htm〉.

8. These results are well known. See for example Albert D. Wheelon, "Free Flight of a Ballistic Missile," American Rocket Society Journal December 1959, pp. 915-926; Frank J. Regan, Re-Entry Vehicle Dynamics (New York: American Institute of Aeronautics and Astronautics, 1984), pp. 65-80.

9. The optimal trajectory corresponds to the choice of the angle $\gamma$ that would minimize the burnout velocity $V$ for a given range $\vartheta$ or, equivalently, maximize the range for a given choice of velocity.

10. The burn time for the first stage of the SLV-3 space launcher that is reportedly used as the booster for the $700 \mathrm{~km}$ range Agni-I missile is 49 seconds. "Stage Data: SLV," available at $\langle$ http://www.astronautix.com/lvfam/slv.htm $\rangle$.

11. "'Strategic N-command to be in Place Next Month'," The Hindu (24 May 2002).

12. Albert D. Wheelon, "Free Flight of a Ballistic Missile," American Rocket Society Journal (December 1959), pp. 915-926, p. 923.

13. This is somewhat related to the well-known Lambert problem which involves finding a Keplerian orbit about a given gravitational center of force connecting two given points in a given time interval. Various methods of solving this are provided in many standard textbooks of astrodynamics. However, in our case, there is no fixed time; rather the time of flight is to be minimized.

14. The significance of drag in a depressed trajectory was estimated by running the numerical calculations with drag set at zero. This reduced the flight time by about $15 \%$ over a range of $600 \mathrm{~km}$.

15. David Wright, "An Analysis of the Pakistani Ghauri Missile Test of April 6, 1988," Science and Global Security, 7 (1998), pp. 227-236. We do not mean to imply that these 
are the real parameters of the Ghauri missile, just that the parameters we have chosen reproduce the range ascribed to the Ghauri missile.

16. See for example J. C. Toomay, Radar Principles for the Non-Specialist (Mendham, NJ: Scitech Publishing, 1998) and Merrill Skolnik, Introduction to Radar Systems (New York: McGraw Hill, 1980).

17. Reproduced from Fig. 2.7 in Merrill Skolnik, op. cit., p. 28.

18. Merrill Skolnik, op. cit., p. 508.

19. "India Acquires Sophisticated Radars from Israel," Indian Express (28 June 2002).

20. See http://www.fas.org/spp/military/program/track/pavepaws.htm

21. See http://www.globalsecurity.org/military/world/india/airbase.htm and http://www.globalsecurity.org/wmd/world/pakistan/facility.htm

22. This, in effect, assumes that the radar is on the path from Sargodha to Delhi which may not be the case. If the radar is not directly under the flight path, then the time taken to detect the missile would be greater.

23. J. C. Toomay, Radar Principles for the Non-Specialist (Mendham, NJ: Scitech Publishing, 1998), p. 89.

24. "Early Warning Sats Set," Aviation Week \& Space Technology (17 March 2003), p. 36 .

25. See Appendix 4 for a table of Indian satellite launches.

26. These satellites weighed about $900 \mathrm{~kg}$, were 7 meters long and 3 meters wide, with a sensor package weighing over $300 \mathrm{~kg}$. The key detector was a 1 meter diameter, 3.6 meter long infrared telescope, with an array of 2,048 lead sulphide detectors which operated in the 2.69-2.95 micron range.

27. Only if it is in equatorial plane; in other cases, the ground track is a figure eight.

28. Jeffrey T. Richelson, America's Space Sentinels: DSP Satellites and National Security (Lawrence, Kansas: University of Kansas Press, 1999), p. 66.

29. Jeffrey T. Richelson, op. cit., p. 71.

30. Jeffrey T. Richelson, op. cit., p. 101.

31. Jeffrey T. Richelson, op. cit., Fig. 5.1, p. 70. The launch dates up to 1997, inclinations, perigee, and apogee of DSP satellites are given in Table C., p. 250.

32. Jeffrey T. Richelson, op. cit., Figure 5.2, p. 80.

33. Jeffrey T. Richelson, op. cit., p. 235-240.

34. John C. Toomay, "Warning and Assessment Sensors," in Ashton B. Carter, John D. Steinbruner, and Charles A. Zraket, eds., Managing Nuclear Operations (Washington DC: Brookings, 1987), p. 303.

35. K. D. Poore, J. Wang, W. B. Rossow, "Cloud Layer Thicknesses from a Combination of Surface and Upper-air Observations," Journal of Climate, 8, 1995, pp. 550568.

36. Pavel Podvig, "History and the Current Status of the Russian Early Warning System," Science and Global Security, 10, No. 1 (2002), pp. 21-60. 
37. "Recent False Alerts From The Nation's Missile Attack Warning System" Report by Senator Gary Hart and Senator Barry Goldwater to Committee on Armed Services United States Senate, October, 9 (Washington DC: U.S. Government Printing Office, 1980), p. 4.

38. "Recent False Alerts From The Nation's Missile Attack Warning System" Report by Senator Gary Hart and Senator Barry Goldwater to Committee on Armed Services United States Senate, October, 9 (Washington DC: U.S. Government Printing Office, 1980), p. 4.

39. Jeffrey T. Richelson, op. cit., p. 96.

40. Bruce G. Blair, The Logic of Accidental Nuclear War (Washington DC: Brookings Institution, 1993), p. 193.

41. Bruce Blair, Strategic Command and Control: Redefining The Nuclear Threat (Washington DC: Brookings, 1985), p. 142-143.

42. We are grateful to Pavel Podvig for this information; see also Geostationary Orbit Catalogue at $\langle$ http://hea-www.harvard.edu/ jcm/space/book/LOGS/logindex/geo.html .

43. Pavel Podvig, loc. cit.

44. 〈http://www.isro.org/gslvd1/gslv05.htm $\rangle$.

45. The apogee was 35,665 kilometer, and perigee 33,806 kilometer, 〈http://www. isro.org/Apr24_2001.htm $>$.

46. 〈http://www.isro.org/Apr18_2001.htm $\rangle$.

47. 〈http://www.isro.org/gslvd1/gslv02.htm .

48. Aviation Week \& Space Technology (12 May 2003), p. 18.

49. In 2002, reportedly to avoid losing its slot in geostationary orbit, Pakistan leased a geostationary satellite, now named Paksat-I, for five years from the American company Hughes Global Services; Bulbul Singh, "Pakistan's Paksat 1 Begins Orbital Move," Aerospace Daily (5 December 2002).

50. TES was launched on October 22, 2001, and weighs $1108 \mathrm{~kg}$; 〈http://www.isro. org/Oct22_2001.html $>$.

51. It is in a $568 \mathrm{~km}$ altitude orbit with period $96 \mathrm{~min}$, apogee $579 \mathrm{~km}$, perigee $551 \mathrm{~km}$, and inclination 97.8 deg.; Space Warn Bulletin, National Space Science Data Center/World Data Center for Satellite Information, No. 576, November 2001, 〈http://nssdc.gsfc.nasa.gov/spacewarn/spx576.html〉.

52. Space Warn Bulletin, loc. cit.

53. Space Imaging, $\langle$ http://www.spaceimaging.com/aboutus/satellites/IKONOS/ikonos. html\#stats $>$.

54. DigitalGlobe, $\langle$ http://www.digitalglobe.com/?goto=products/quickbird $\rangle$.

55. Ikonos has $1 \mathrm{~m}$ resolution up to 26 degrees (0.45 radians) off-nadir, at $680 \mathrm{~km}$ altitude. The imagery would thus be at least one-meter ground resolution for about $680 \mathrm{~km} \times 0.45$ radians to either side of nadir.

56. Space Imaging, 〈http://www.spaceimaging.com/aboutus/corpFAQ.htm\#ikonos〉.

57. DigitalGlobe, loc. cit. 
58. Ministry of Defense, 2001-2002 Annual Report, Government of India, New Delhi, p. 45 .

59. See Appendix 5 for a table of the image resolution required for identification of various military facilities, equipment and weapons systems.

60. 〈http://www.indianembassy.org/policy/CTBT/nuclear_doctrine_aug_17_1999.html〉.

61. We note that these procedures would not be applicable to the case of nuclear attacks from off-shore ballistic missile submarines where flight times are about 10 or 15 minutes.

62. Bruce G. Blair, op. cit., pp. 188-189. For another reconstruction, see Michael D. Wallace, Brian L. Crissey, Linn I. Sennott, "Accidental Nuclear War: A Risk Assessment," Journal of Peace Studies, Vol. 23. No. 1 (March 1986), pp. 9-27.

63. See Pavel Podvig, "The Operational Status of the Russian Space-Based Early Warning System," Science and Global Security, Vol. 4. No. 3 (1994), pp. 363-384; and Pavel Podvig, "History and Current Status of the Russian Early Warning System," Science and Global Security Vol. 10. No. 1 (2002), pp. 21-60.

64. Bruce G. Blair, Global Zero Alert for Nuclear Forces (Washington DC: Brookings Institution, 1995), pp. 46-50.

65. According to another description, the "missile attack" signal is sent to the terminals of the Kazbek system, which is accessible to the President, the Defense Minister, and the Chief of General Staff. Pavel Podvig, ed., Russian Strategic Nuclear Forces (Cambridge, MA: The MIT Press, 2001), p. 438.

66. The "missile attack" signal can also be transmitted if there is credible information about two or more launches from only the radar systems, without a signal from the satellites. Pavel Podvig, ed., Russian Strategic Nuclear Forces (Cambridge, MA: The MIT Press, 2001), p. 438.

67. Bruce G. Blair, Global Zero Alert for Nuclear Forces (Washington DC: Brookings Institution, 1995), pp. 50-51.

68. Bruce Blair, The Logic of Accidental Nuclear War (Washington, DC: Brookings Institution Press, 1993), f.n. 46, pp. 342-343. Also see H. L. Abrams, "Strategic Defense and Inadvertent Nuclear War," in Inadvertent Nuclear War: The Implications of the Changing Global Order, eds. H. Wiberg, I.D. Petersen, and P. Smoker (Oxford: Pergamon Press, 1993), pp. 39-55.

69. "Recent False Alerts From The Nation's Missile Attack Warning System" Report by Senator Gary Hart and Senator Barry Goldwater to Committee on Armed Services United States Senate, October, 9 (Washington DC: U.S. Government Printing Office, 1980), p. 4.

70. Bruce G. Blair, The Logic of Accidental Nuclear War (Washington DC: Brookings Institution, 1993), p. 194.

71. Bruce G. Blair, Harold A. Feiveson, and Frank von Hippel, "Taking Nuclear Weapons off Hair-Trigger Alert," Scientific American (November 1997).

72. An example of what came close to being a common mode failure was the case of the January 1968 crash of a B-52 over the early warning radar installed at Thule, Greenland. There was concern that the breakdown of communication from the radar could have been mistaken as an attack on the radar, a likely precursor to a full scale nuclear attack. To minimize such a misunderstanding, a B-52 bomber was constantly 
on airborne patrol over the radar to provide confirmation that the radar had not been attacked. If the bomber which crashed had destroyed the radar in the process, that would have given a dual signal to NORAD that a Soviet attack was underway, leading to increased alerts and possibly a nuclear attack. Scott Sagan, The Limits of Safety: Organizations, Accidents and Nuclear Weapons (Princeton: Princeton University Press, 1993), pp. 156-203.

73. It has been argued that in complex systems accidents are inevitable. See Charles Perrow, Normal Accidents: Living with High-Risk Technologies (New York: Basic Books, 1984).

74. “Israel Boosts Indian Missile Defence Hope," Indian Express (15 February 2003).

75. For an elaboration of this argument see M. V. Ramana, "Risks of Launch on Warning Posture," Economic and Political Weekly (1 March 2003), pp. 860-864.

76. The derivation largely follows Frank J. Regan, Re-Entry Vehicle Dynamics (New York: American Institute of Aeronautics and Astronautics, 1984), pp. 65-80.

77. See for example Lisbeth Gronlund and David Wright, "Depressed Trajectory SLBMs: A Technical Evaluation and Arms Control Possibilities," Science and Global Security 3, no. 1-2 (1992), pp. 101-159. As discussed earlier, we ignore corrections from oblateness and rotation of the Earth.

78. This is not strictly true. Apart from variations in fuel burning, because atmospheric pressure decreases with increasing altitude, the thrust and specific impulse will increase as the vehicle is propelled to higher altitudes; this change could be of the order of 10 $30 \%$ of the overall thrust. See George P. Sutton and Oscar Biblarz, Rocket Propulsion Elements (New York: John Wiley, 2001), p. 33. We therefore use an average specific impulse.

79. In reality, the problem is more complicated. Missiles are usually not flown to the maximum possible range. In order to reach a particular target that is closer than the maximum range at a fixed angle of flight, there are two possibilities. One is to terminate the thrust of the missile before all the fuel is consumed. The alternative is to waste some of the energy expended by the fuel by going on a longer flight path during the boost phase but ending up with the desired velocity and angle of flight at the end of boost. This is called General Energy Management (GEM) steering. See Paul Zarchan, Tactical and Strategic Missile Guidance (New York: American Institute of Aeronautics and Astronautics, 1997), pp. 281-289.

80. See for example Lisbeth Gronlund and David Wright, loc. cit.

81. Frank J. Regan, op. cit., pp. 229-231.

82. National Aeronautics \& Space Administration, U.S. Standard Atmosphere, 1976 (Washington, DC: U.S. Department of Commerce, National Technical Information Service, 1976).

83. This follows the discussions in Merrill Skolnik, Introduction to Radar Systems (New York: McGraw Hill, 1980) and J. C. Toomay, Radar Principles for the Non-Specialist (Mendham, NJ: Scitech Publishing, 1998).

84. J. C. Toomay, Radar Principles for the Non-Specialist (Mendham, NJ: Scitech Publishing, 1998), p. 69.

85. See for instance figure 2.11 in Merrill Skolnik, Introduction to Radar Systems (New York: McGraw Hill, 1980), p. 35. 


\section{APPENDIX 1. BALLISTIC MISSILE DYNAMICS}

\section{Analytical Results}

Though the ballistic phase is routinely treated in standard textbooks on rockets and missiles, it is worth presenting the derivations here to show how easily they may be obtained starting from elementary ideas of Newtonian mechanics as applied to the Kepler problem. ${ }^{76}$ Assuming, to start with, that the Earth is a perfect sphere of mass $M$, it will give rise to a gravitational force of magnitude $G M m / r^{2}$ towards its center on a body of mass $m$. Because this is a central force, angular momentum will be conserved. Hence the orbit will lie on a plane described by polar coordinates $(r, \theta)$ with the Earth's center being taken as the origin. The Newtonian equations of motion in these polar coordinates are:

$$
\begin{array}{r}
\ddot{r}-r(\dot{\theta})^{2}+\mu / r^{2}=0 \\
r \ddot{\theta}+2 \dot{r} \dot{\theta}=\frac{1}{r} \frac{d\left(r^{2} \dot{\theta}\right)}{d t}=0,
\end{array}
$$

where $\mu=M G$. The second equation represents the conservation of angular momentum (per unit mass), i.e., $l \equiv r^{2}(d \theta / d t)$ is a constant. This can be used to eliminate the variable $t$ in favor of $l$ and $\theta$ by equating the operator $d / d t$ with $\left(l / r^{2}\right)(d / d \theta)$. Then the first equation may be rewritten as:

$$
\frac{d^{2} u}{d \theta^{2}}+u=\frac{\mu}{l^{2}}
$$

where $u \equiv(1 / r)$. This is the orbit equation. Clearly it is mathematically the same as the equation of a one-dimensional oscillator $u(\theta)$ acted upon by an additional constant force $\left(\mu / l^{2}\right)$ and is easily integrated to give:

$$
u=A \cos \theta+B \sin \theta+\frac{\mu}{l^{2}}
$$

This is the equation of conic sections in polar coordinates. The constants $\mathrm{A}$ and $\mathrm{B}$ are obtained from the boundary conditions at the end of the boost phase that is assumed to be located at some height $h$ above the surface of the earth (of radius $R$ ). The Keplerian free fall or ballistic phase begins at this point, which will be taken to correspond to $\theta=0$. The boundary conditions 
are:

$$
u(0)=\frac{1}{R+h} \quad \text { and } \quad \frac{d u}{d \theta}(0)=\frac{-\tan \gamma}{R+h}
$$

where $\gamma$ is the angle between the local horizontal and the missile velocity at the start of the ballistic (end of boost) phase. Using these boundary conditions in Eq. (A1.3) we get

$$
\frac{1}{r}=\frac{\mu(1-\cos \theta)}{l^{2}}+\frac{\cos (\theta+\gamma)}{(R+h) \cos \gamma}
$$

Next, let $\vartheta$ be the range angle, i.e., the value of the angle $\theta$ at the end of the ballistic phase, where the missile reenters the atmosphere. This will occur near the target at some height $h_{2}$ above the ground. This height $h_{2}$ is somewhat arbitrary since the atmosphere does not have a sharp boundary; $h_{2}$ represents its effective thickness. Inserting $\left(r=R+h_{2}\right.$ at $\left.\theta=\vartheta\right)$, we get:

$$
\frac{1}{R+h_{2}}=\frac{\mu(1-\cos \vartheta)}{l^{2}}+\frac{\cos (\vartheta+\gamma)}{(R+h) \cos \gamma}
$$

Recall that $l$ here refers to the conserved angular momentum per unit mass. Its (initial) value is $l=V(R+h) \cos (\gamma)$. Equation (A1.6) can therefore be inverted to give an expression for the burnout speed $V$ as a function of the range angle $\theta_{T}$ and the burnout angle $\gamma$ :

$$
V^{2}=\frac{\mu(1-\cos \vartheta)}{\left(\frac{R+h}{R+h_{2}}-\frac{\cos (\vartheta+\gamma)}{\cos \gamma}\right)(R+h) \cos ^{2} \gamma}
$$

One can obtain the optimal value of the burnout angle $\gamma$ which would minimize the velocity $V$ for a given range $\vartheta$ by maximizing the denominator of Eq. (A1.7) with respect to $\gamma$. This gives an optimal angle:

$$
\gamma_{\mathrm{op}}=\frac{\sin \vartheta}{\frac{R+h}{R+h_{2}}-\cos \vartheta}
$$

Equivalently, this choice of burnout angle $\gamma$ would maximize the range for a given burnout velocity.

Finally the total time of flight $T$ during the ballistic phase may be calculated by using the relation $l \equiv r^{2} d \theta / d t$ to get $T=\int d t=\frac{1}{l} \int_{0}^{\vartheta} d \theta r^{2}(\theta)$. Upon 
substituting in the integrand Eq. (A1.5) which gives the function $r(\theta)$ and doing the tedious but straightforward integral over $\theta$ one gets:

$$
\begin{aligned}
T= & \frac{R+h}{V \cos \gamma}\left[\frac{\tan \gamma(1-\cos \vartheta)+(1-\lambda) \sin \vartheta}{(2-\lambda)\left[\frac{1-\cos \vartheta}{\lambda \cos ^{2} \gamma}+\frac{\cos (\vartheta+\gamma)}{\cos \gamma}\right]}\right. \\
& \left.+\frac{2 \cos \gamma}{\lambda\left(\frac{2}{\lambda}-1\right)^{\frac{3}{2}}} \tan ^{-1}\left[\frac{\left(\frac{2}{\lambda}-1\right)^{\frac{1}{2}}}{\cos \gamma \cot (\vartheta / 2)-\sin \gamma}\right]\right],
\end{aligned}
$$

where $\lambda=V^{2}(R+h) / \mu$. Equations (A1.7) and (A1.9) are standard exact results for the ballistic phase in the gravity field of an idealized perfectly spherical Earth.

These results can be simplified by making some approximations that are good to an accuracy of a few percent for typical South Asian missile flights. To start with, one can neglect $h$, the burnout altitude and $h_{2}$, the effective thickness of the atmosphere. A typical burnout altitude for single stage missiles like the Prithvi or the Scud is about $30 \mathrm{~km}$; for two stage missiles like the Agni, it is about $100 \mathrm{~km}$. The atmospheric density drops rapidly with increasing altitude, decreasing to a hundredth of the sea-level value by an altitude of $30 \mathrm{~km}$. These numbers are much smaller than the radius of the earth, which is about 6370 kilometers. If we neglect these heights $h$ and $h_{2}$ as compared to $R$ the radius of the earth, then Eq. (A1.7) simplifies to:

$$
V^{2}=\frac{\mu}{R \cos \gamma} \frac{(1-\cos \vartheta)}{(\cos \gamma-\cos (\vartheta+\gamma))}=\frac{\mu}{R \cos ^{2} \gamma} \frac{1}{(1+\tan \gamma \cot \vartheta / 2)} .
$$

The optimal angle Eq. (A1.8) reduces in this $h, h_{2} \ll R$ limit to:

$$
\tan \left(2 \gamma_{\mathrm{op}}\right)=\frac{\sin \vartheta}{1-\cos \vartheta}=\cot (\vartheta / 2) \Rightarrow \gamma_{\mathrm{op}}=\frac{\pi-\vartheta}{4}
$$

\section{Numerical Calculations of Missile Trajectories}

Capturing the complexities of the boost and reentry phases and aerodynamics in the atmosphere as well as the detailed characteristics of individual missiles requires numerical analysis. In this subsection we will present the details of such numerical calculations. We used Matlab (Version 5.0) for these calculations. 
The full set of equations governing the entire trajectory are the same Newtonian laws used earlier in the ballistic phase with the effects of thrust and drag included. They can be written as: ${ }^{77}$

$$
\begin{aligned}
\frac{d v}{d t} & =\frac{T \cos (\eta)}{m(t)}-\frac{C_{d} \rho A v^{2}}{2 m(t)}-g \sin (\gamma), \\
\frac{d \gamma}{d t} & =\frac{d \psi}{d t}+\frac{T \sin (\eta)}{v m(t)}-\frac{g \cos (\gamma)}{v}, \\
\frac{d \psi}{d t} & =\frac{v \cos (\gamma)}{(R+h)} \\
\frac{d h}{d t} & =v \sin (\gamma), \text { and } \\
\frac{d m}{d t} & =\frac{T}{g_{0} I_{\mathrm{sp}}},
\end{aligned}
$$

where $v$ is the velocity at time $t, T$ is the thrust, $\eta$ is the angle between the thrust and the velocity, $m$ is the mass at time $t, C_{d}$ is the drag coefficient, $\rho$ is the density of air as a function of the altitude, $A$ is the area of cross section of the missile, $\gamma$ (often called the flight path angle) is the angle between the thrust and the local horizontal, $\psi$ is the angular range, $h$ is the height above Earth, and $g$ is the local acceleration due to gravity as a function of the altitude. $I_{\mathrm{sp}}$ is the specific impulse, a measure of the energy content of the propellant and is the thrust generated by burning unit mass of propellant in unit time. We have followed the standard convention wherein a factor of $g_{0}$, the acceleration due to gravity at sea level $\left(9.8 \mathrm{~m} / \mathrm{s}^{2}\right)$ is pulled out in common, thus leaving the specific impulse with the dimensions of time. We assume that the thrust of the missile is a constant during the boost phase and zero thereafter. ${ }^{77}$ The (average) thrust during boost phase is given by:

$$
T=\frac{g_{0} M_{\mathrm{prop}} I_{\mathrm{sp}}}{t_{\text {burnout }}}=\frac{9.8 M_{\mathrm{prop}} I_{\mathrm{sp}}}{t_{\text {burnout }}}
$$

Though not exactly known, approximate values for most quantities of interest are available from the public record. The one quantity that is usually not specified is $\eta$, the angle between thrust and velocity as a function of time. ${ }^{79}$ In solving these equations, we will vary $\eta$ to obtain the desired range or minimize the time of flight. 


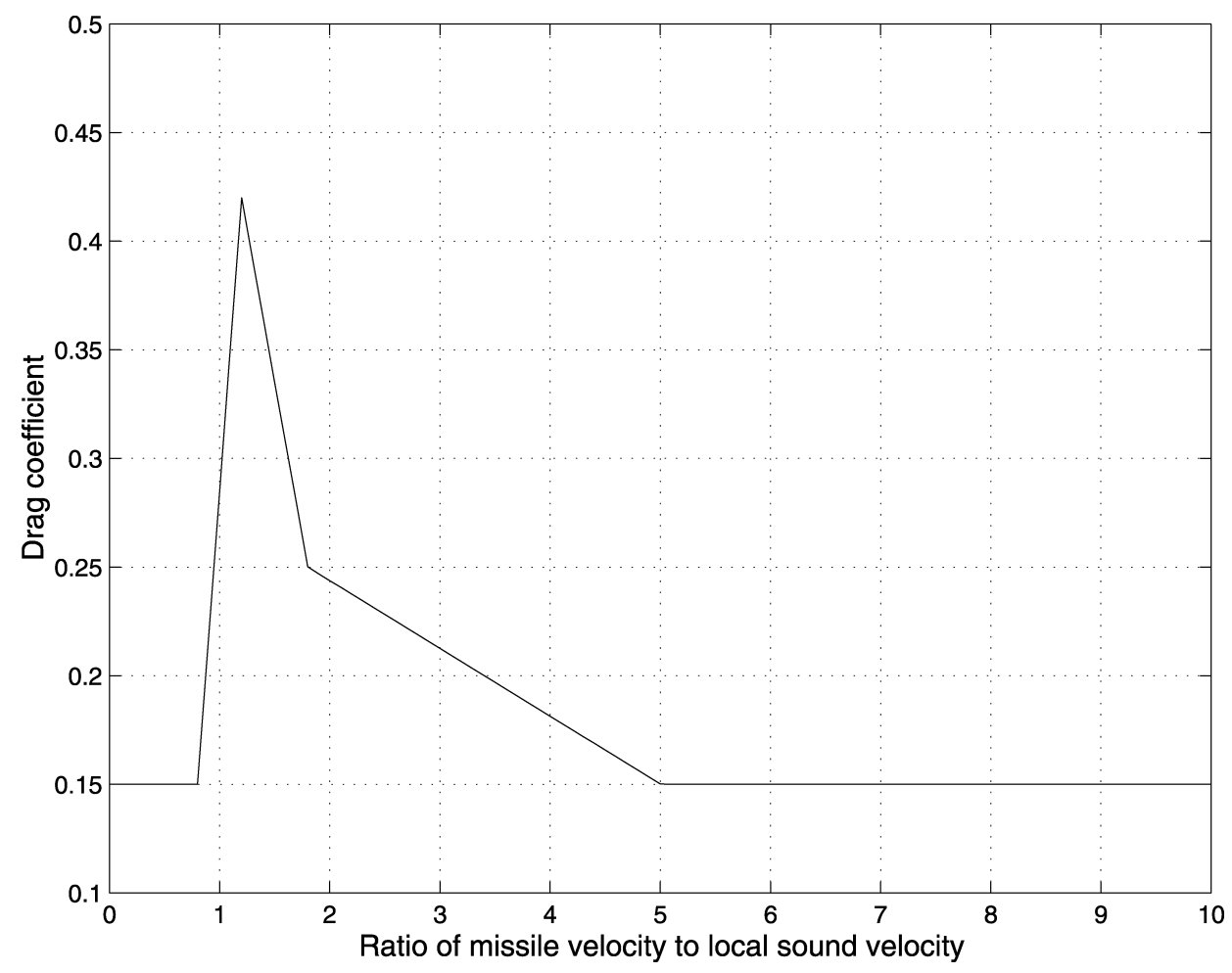

Figure 3: Drag coefficient of missile.

The drag coefficient $C_{d}$ during boost phase is assumed to be the same as the measured values for the V-2 rocket and is shown in Figure 3 as a function of the ratio of the velocity of the missile to the local sound velocity. ${ }^{80}$

We will assume that the missile jettisons the propellant tanks at the end of the boost phase. In that case all that would be left would be the missile nose cone, which is assumed to be a hemisphere mounted on a blunted cone. The drag coefficient $C_{d}$ of the missile during reentry then is given by: $C_{d}=2 \sin ^{2}(\alpha)+\left(\frac{r_{n}}{r_{b}}\right)^{2}\left(1-2 \sin ^{2}(\alpha)-\sin ^{4}(\alpha)\right)$, where $\alpha$ is half the cone opening angle, $r_{n}$ is the radius of the frontal hemisphere and $r_{b}$ is the base radius of nose cone. ${ }^{81}$ The density of air and the local speed of sound (needed to calculate the drag coefficient) as functions of altitude are taken from the 1976 U.S. standard atmosphere and are shown in Figure 4 and Figure $5 .^{82}$ 


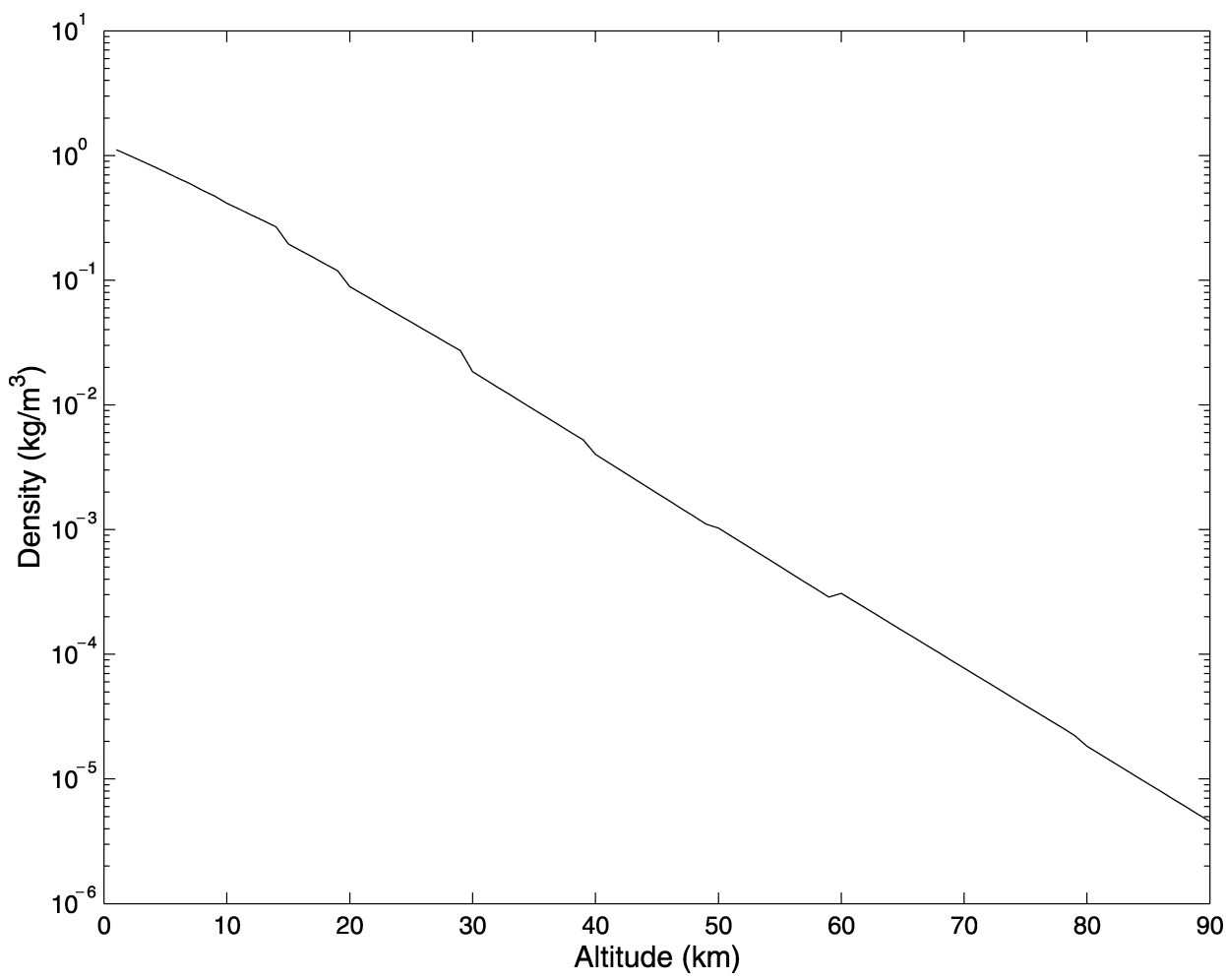

Figure 4: Atmospheric density as a function of altitude.

\section{APPENDIX 2. EFFECT OF EARTH'S ROTATION}

Consider a simple example in which we have, in the earth-fixed frame, a launch site $\boldsymbol{r}_{B}$ and a target $\boldsymbol{r}_{T}$, both at the ground level, at the same latitude $L$ and separated by a longitude difference of $\psi_{0}$. As the earth rotates, $\boldsymbol{r}_{B}(t)$ and $\boldsymbol{r}_{T}(t)$ will both change with time in any fixed inertial frame. Let us choose the inertial frame as one whose spherical polar angles coincide with the geographical latitude and longitude at $t=0$. Then at the start of the missile trajectory, the azimuthal angle separation $\psi_{t=0}$ between launch and target is just the longitude difference. As the missile travels the target moves along the azimuthal direction due to earth's rotation, reaching a final azimuthal angle separation $\psi_{T}$ given by:

$$
\psi_{T}=\psi_{0}+\Omega T
$$


144 Mian et al.

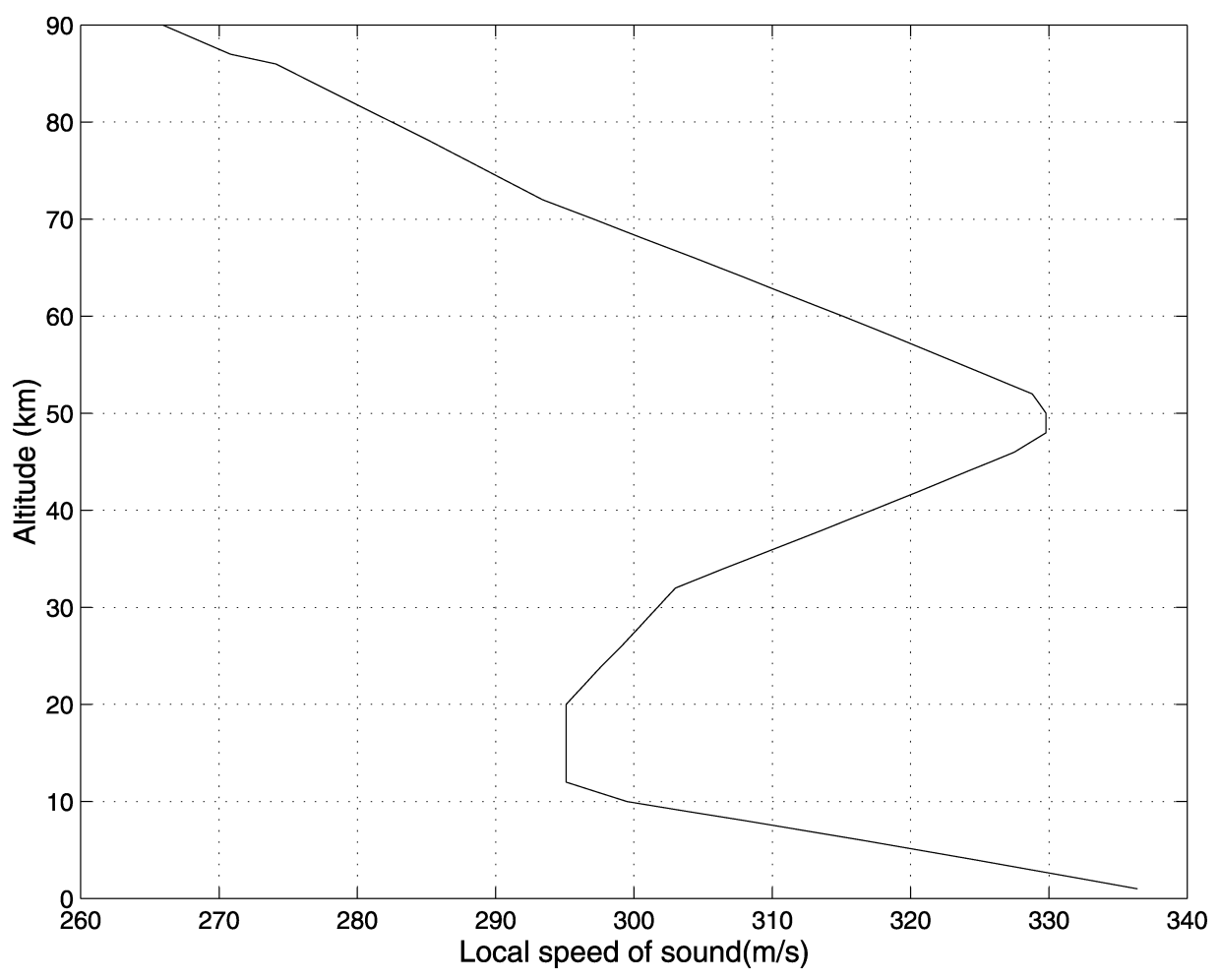

Figure 5: Local speed of sound as a function of altitude.

Then the range angle subtended by the trajectory at the Earth's center $\vartheta$ in the inertial frame, is given by:

$$
\cos \vartheta=\frac{\vec{r}_{B}(0) \cdot \vec{r}_{T}(T)}{R^{2}}=\cos ^{2} L \cos \psi_{T}+\sin ^{2} L
$$

In the small range approximation which, as we have seen in the Missile Flight Dynamics section of this article, is quite good for South Asian examples, both the angles $\vartheta$ and $\psi_{T}$ can be taken to be small.

Then Eq. (A2.2) can be approximated by:

$$
\begin{aligned}
1-\frac{\vartheta^{2}}{2} & \cong \cos ^{2} L\left(1-\frac{\psi_{T}^{2}}{2}\right)+\sin ^{2} L, \text { or } \\
\vartheta & \approx \cos L \cdot \psi_{T}=\cos L \cdot\left(\psi_{0}+\Omega T\right) .
\end{aligned}
$$


Let us insert this into the small angle result (Eq. 5) for the transit time to get:

$$
T=\frac{R \cos L\left(\psi_{0}+\Omega T\right)}{V \cos \gamma}
$$

Here $V$ and $\gamma$ refer to the boost speed and tilt angle of the missile, in the inertial frame. They differ from the corresponding quantities $V_{0}$ and $\gamma_{0}$ in the Earth's frame because of the Earth's rotation, which is along the azimuthal direction. We remember that in this example, with both launch and target points being at the same latitude $L$, the horizontal component of the boost velocity in both frames as well as the extra velocity imparted by earth's rotation will all be along the latitude. Clearly,

$$
V \cos \gamma=V_{0} \cos \gamma_{0}+\Omega R \cos L
$$

Hence,

$$
\begin{aligned}
T & =\frac{R \cos L\left(\psi_{0}+\Omega T\right)}{V_{0} \cos \gamma_{0}+\Omega R \cos L} \\
& =\left(T_{0}+\frac{\Omega R T \cos L}{V_{0} \cos \gamma_{0}}\right)\left(1+\frac{\Omega R \cos L}{V_{0} \cos \gamma_{0}}\right)^{-1},
\end{aligned}
$$

where

$$
T_{0}=\frac{R \cos L \psi_{0}}{V_{0} \cos \gamma_{0}}
$$

would have been the transit time had the Earth's rotation been absent. Clearly $T=T_{0}+O(\Omega)$. Hence we can write A2.6 as:

$$
\begin{aligned}
T & =\left(T_{0}+\frac{\Omega R \cos L\left(T_{0}+O(\Omega)\right)}{V_{0} \cos \gamma_{0}}\right)\left(1+\frac{\Omega R \cos L}{V_{0} \cos \gamma_{0}}\right)^{-1} \\
& =T_{0}+O\left(\Omega^{2}\right)
\end{aligned}
$$

Thus we see that to leading order in $\Omega$, the transit time does not get altered by earth's rotation. The correction would be of order $\Omega^{2}$. More precisely, the fractional correction to the transit time would of the order of the dimensionless parameter $\kappa \equiv(R \Omega / V)^{2}$ where $R=6370 \mathrm{~km}$ is the earth radius, $\Omega=7.29 \times$ $10^{-5}$ radians per second and $V$, the typical missile speed, can be taken to be about $3 \mathrm{~km} / \mathrm{sec}$. With these values the correction to the orbit time will be about 
$2.4 \%$. That is only about 12 seconds for the Sargodha-Delhi flight lasting 8 minutes.

This calculation was for the specially convenient case of a latitudinal orbit. But it suggests that in general for South Asian orbits, the effect of earth's rotation on transit time will not be significant enough to affect any questions of early warning strategy or policy.

\section{APPENDIX 3. RADAR FUNDAMENTALS AND CROSS SECTIONS ${ }^{83}$}

Let us suppose that the radar has emitted one pulse of duration $\tau$ seconds and power $P_{t}$ Watts into a solid angle $\Omega$ steradians. The energy flux due to this pulse at a distance $r$ meters from the radar is given by:

$$
F_{e}=\frac{\tau P_{t}}{\Omega r^{2}}
$$

Any target at this distance which is exposed to this flux will reradiate a fraction of the energy it intercepts. The amount of reradiated energy and its angular distribution would in general be complicated and depend on the radar wavelength and the geometry and other characteristics of the target. These complications are lumped into a single factor called the radar cross section (denoted by $\sigma$ ) which is defined through the equation:

$$
F_{r}=\frac{\sigma F_{e}}{4 \pi r^{2}}
$$

where $F_{r}$ is the reflected energy per unit area received by the radar. The signal $S$ that the radar receiver of area $A$ detects is therefore:

$$
S=A F_{r}=\frac{\tau P_{t} \sigma A}{4 \pi \Omega r^{4}}
$$

Notice that the signal falls off as the fourth power of the distance to the target. The signal calculated above pertains to the detection using a single pulse. But since a radar keeps emitting pulses continuously, the signal can be enhanced by multiple hits of the target by many pulses. If $n$ reflected signals are coherently added up, the resulting signal-to-noise $(S / N)$ ratio will go up by a factor of $n$. In reality, fully coherent superposition of the $n$ signals may not be achievable. To account for this, we will henceforth use $n$ to stand for the effective enhancement factor. 
The process of radar detection also has to contend with system losses (denoted by $L$ ) and background noise from a variety of sources. The combined noise energy $N$ is described by a effective noise temperature $T_{s}$ and equals $k T_{s}$ where $k=1.38 \times 10^{-23} \mathrm{~J} / \mathrm{deg}$. Combining these different elements, we get the basic radar equation:

$$
\frac{S}{N}=\frac{n \tau P_{t} \sigma A}{4 \pi \Omega r^{4} k T_{s} L} .
$$

In the radar literature, this equation is presented in a number of equivalent forms. For example, a quantity called Gain $(G=4 \pi / \Omega)$ is often defined; this measures the ability of the radar to focus its power output into a solid angle $\Omega$. The factor $\Omega$ can be replaced by $4 \pi / G$ to give one commonly used form. Similarly, assuming that the gain is limited only by diffraction, $G$ itself can be replaced by $4 \pi A / \lambda^{2}$.

From the radar Eq. (A3.4) we can see that, for a given signal to noise ratio $S / N$ decided upon as optimal, the distance up to which the radar can detect the target is given by:

$$
R_{d}=\left(\frac{n \tau P_{t} \sigma A}{4 \pi \Omega k T_{s} L\left(\frac{S}{N}\right)}\right)^{\frac{1}{4}}
$$

The literature often refers to $R_{d}$ as the radar range but we emphasize that this quantity depends on the cross section which can vary by orders of magnitude depending on the orientation of the target. For example, a missile that is coming straight towards the radar (nose-on), would have a cross section determined by the small area of its nose cone. Whereas, the cross section of the same missile when viewed sideways during launch is greater because of the larger area that is normal to the radar beam.

\section{The Search Mode}

When used for early warning of missile attacks, a radar has to scan a large segment $\left(\Omega_{s}\right)$ of the sky from which the missile is likely to come. Typically $\Omega_{s}$ is a few steradians of solid angle. (One hemisphere of the sky corresponds to $2 \pi$ steradians.) The beam width (solid angle) of the radar $(\Omega)$, on the other hand, is much smaller so as to increase the power density of the beam. For example, a radar whose diameter is 5 meters operating with a wavelength of $25 \mathrm{~cm}$ ( $L$ band) has a limiting beam width $\Omega$ of 0.0025 steradians. Therefore, the radar beam has to scan the desired area of the sky. One can imagine dividing 
the scan area into angular bins set by the beam width of the radar. The radar beam, then, would have to move from bin to bin, covering the entire area over a period of time called the scan time $\left(t_{s}\right)$.

In this scan mode, it is customary to write the radar equation in terms of the average power emitted by the radar during a single scan of the area of interest. This is related to the peak power $\left(P_{t}\right)$ through:

$$
P_{\mathrm{ave}}=\frac{n P_{t} \tau}{t_{s}}\left(\frac{\Omega_{s}}{\Omega}\right)
$$

The range equation can be rewritten in terms of $P_{\text {ave }}$ as:

$$
R_{d}=\left(\frac{t_{s} P_{\mathrm{ave}} \sigma A}{4 \pi \Omega_{s} k T_{s} L\left(\frac{S}{N}\right)}\right)^{\frac{1}{4}}
$$

\section{Radar Cross Sections}

An important figure for the purposes of calculating the radar detection range is the radar cross section $\sigma$, which is implicitly defined through Eq. (A3.2). Due to the complexities of the interaction of the radar beam with the target, this is not the same as the geometrical cross section of the target as seen from the radar. Rather, as evident from Eqs. (A3.2-A3.3), it is the geometrical cross section of an equivalent ideal isotropic reflector. If the target were to be a perfectly conducting spherical target whose radius $a$ is much larger than the radar wavelength $\lambda$ and which reradiates all the energy impinging on it, $\sigma$ would be its geometrical cross section.

Any real target will reemit the incident radiation nonisotropically, and its effective radar cross section will depend on its shape and size and on the radar wavelength because of diffractive effects. Standard radar textbooks calculate this cross section for several different shapes and sizes. Of particular interest to us are the cross sections of a missile at launch (side-on) and with the nose cone pointing at the radar.

To first approximation, one could treat a side-on missile as a cylinder of length $l$ and diameter $d$. The radar cross section of the cylinder will be greater than the geometric cross section $(l d) .{ }^{84}$ While the reflection in the plane perpendicular to the cylinder's axis will be isotropic, reflection along the axis will only have a diffractive width of order $l / \lambda$. The resulting angular gain leads to an effective cross section for the cylinder of:

$$
\sigma_{\mathrm{cyl}}=l d \times \pi l / \lambda=\pi l^{2} d / \lambda .
$$


If we choose values typical of single stage missiles $(l=10 \mathrm{~m}, d=1.5 \mathrm{~m})$ and a radar wavelength of $0.25 \mathrm{~m}$, then we get a value of $\sigma \approx 188 \mathrm{~m}^{2}$.

If the missile is observed after boost phase and the payload has separated from the rocket boosters, what is relevant is the cross section of the nose cone alone. The limiting case would be if this were to be coming straight at the radar. Assuming its shape to be a cone-sphere, the cross section is just the geometrical value of $\pi a^{2}$ for $\lambda \ll 2 \pi a$. But as the nose cone's radius becomes smaller and comparable to $\lambda$, the cross section begins to oscillate between values of $0.5 \lambda^{2}$ and $0.05 \lambda^{2}$ because of interference between the direct radiation of the target and the radiation from the induced surface currents on it. ${ }^{85}$ Typically, radar wavelengths and nose sphere radii tend to be of the same order, around $10-20 \mathrm{~cm}$. So the precise value of the cross section will depend on the actual values of $a$ and $\lambda$. But a good estimate would be to take $\sigma \approx 0.1 \lambda^{2}$. For the L-band Greenpine radar with $\lambda \approx 0.25 \mathrm{~m}$, the cross section is about $6.10^{-3} \mathrm{~m}^{2}$.

\section{APPENDIX 4: INDIAN SATELLITE LAUNCHES}

Table 6: Indian satellite launches.

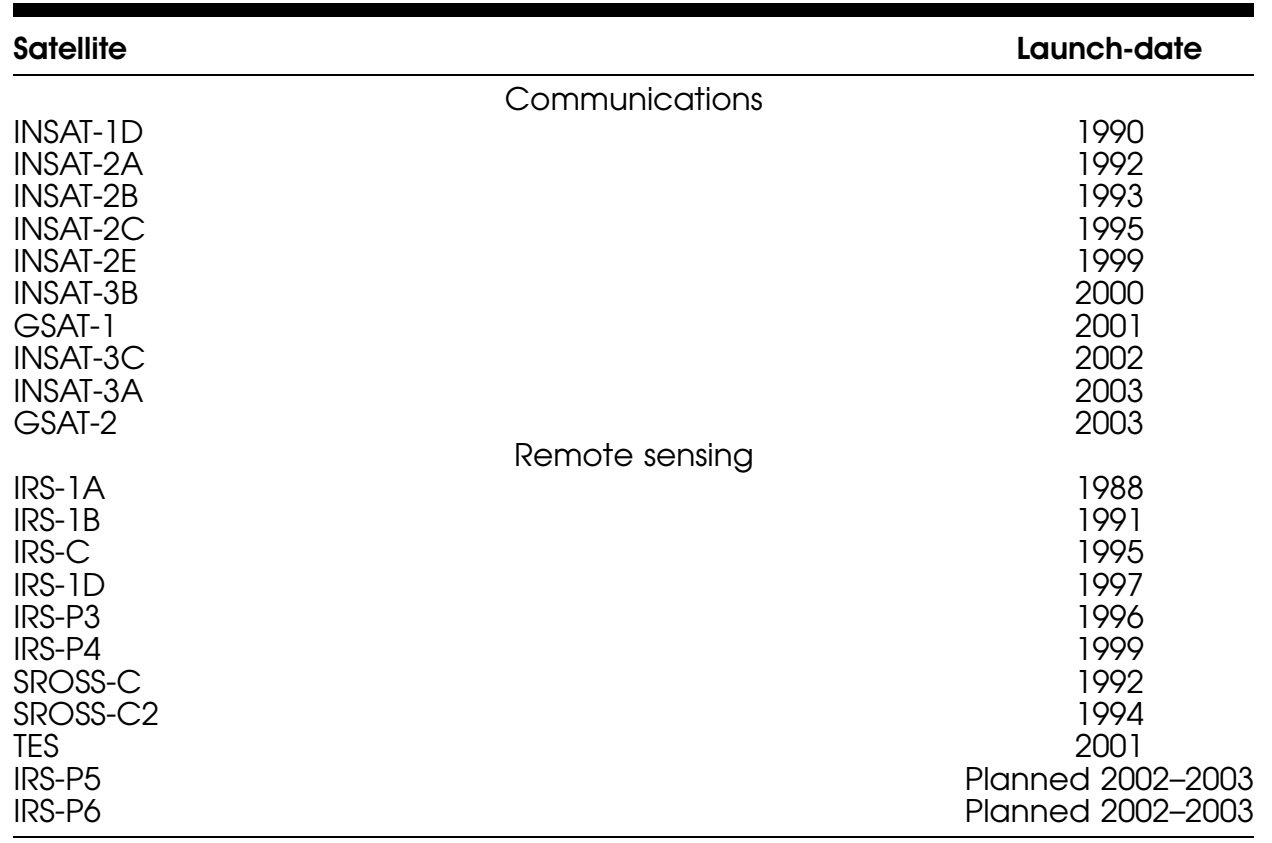

Source: Indian Space Research Organization website at 〈http://www.isro.org). 
150 Mian et al.

\section{APPENDIX 5: CAPABILITIES OF OPTICAL SATELLITES}

Table 7: Resolution in meters for detecting significant military capabilities.

\begin{tabular}{lcc}
\hline Target & Detection & Precise identification \\
\hline Surfaced submarines & $7.5-30$ & 1.5 \\
Surface ships & $7.5-15$ & 0.6 \\
Bridges & 6 & 1.5 \\
Troop units & 6 & 1.2 \\
Airfield facilities & 6 & 3 \\
Radar & 3 & 0.3 \\
Aircraft & 4.5 & 1 \\
Command and control headquarters & 3 & 1 \\
Supply Dumps & $1.5-3$ & 0.3 \\
Missile sites & 3 & 0.6 \\
Rockets and artillery & 1 & 0.15 \\
Nuclear weapons components & 2.5 & 0.3 \\
\hline
\end{tabular}

Source: Jeffrey T. Richelson, "Implications for Nations Without Space-based Intelligence Collection Capabilities," in Michel Krepon, Peter Zimmerman, Leonard Spector, and Mary Umberger, eds., Commercial Observation Satellites and International Security (New York: St Martin's Press, 1990), Table 6.1, p. 60. 